\title{
Human capital in a global and knowledge-based economy
}

\section{FINAL REPORT}

\author{
Angel de la Fuente* \\ Instituto de Análisis Económico (CSIC) \\ and \\ Antonio Ciccone \\ Universitat Pompeu Fabra
}

May 2002

$\left(^{*}\right)$ We are grateful to V. Campanelli, L. de Almeida, S. Wright, L. Ferreira and the rest of the participants in a seminar held at the DG for Employment and Social Affairs for their helpful comments and suggestions. We would also like to thank Ana Belmonte, Dörte Domeland-Narváez, Juan Antonio Duro, Marta Felis, Uwe Sunde and Paolo Vanin for their competent assistance in the preparation of this report. 


\section{TABLE OF CONTENTS}

$\begin{array}{lr}\text { Executive summary } & 4\end{array}$

$\begin{array}{lr}\text { Main report } & 9\end{array}$

1. Introduction 9

2. Human capital and productivity in the knowledge economy 10

3. Empirical evidence on human capital and productivity 12

a. Human capital and labour market outcomes: microeconomic evidence $\quad 14$

i. Methodological issues in estimating the effect of formal schooling on wages 15

ii. Review of the estimates obtained with different methodologies 16

$\begin{array}{ll}\text { iii. Trends of the Mincerian returns to schooling over time } & 17\end{array}$

$\begin{array}{ll}\text { iv. Differences across European countries } & 17\end{array}$

$\begin{array}{ll}\text { v. Female-male wage differentials } & 18\end{array}$

vi. Effects of education on unemployment and labour force participation $\quad 18$

$\begin{array}{ll}\text { vii. The rate of return to education } & 20\end{array}$

viii. On-the-job training, human capital and productivity at the firm level 21

ix. Technological change and the effect of human capital on wages 22

x. Technological change and employment 24

xi. Non-market returns to schooling 24

b. Human capital and growth: macroeconomic evidence 25

i. Human capital in growth theory 25

ii. Empirical formulations 26

iii. Econometric issues $\quad 29$

iv. A brief review of the empirical evidence 32

v. Externalities at the city and regional levels 33

4. Social capital and growth 34

5. Some tentative conclusions 36

a. A plausible range of parameter estimates 36

b. Implications for growth and cross-country disparities in the OECD 39

c. Rates of return to schooling and some policy implications 43

6. Concluding remarks 51

References $\quad 54$ 
1. Human capital, productivity and earnings $\quad 61$

a. Estimating the individual return to schooling: methodological issues 61

b. Review of the estimates 63

$\begin{array}{ll}\text { c. The return to schooling over time and across countries } & 65\end{array}$

$\begin{array}{ll}\text { d. The role of schooling for male-female wage differentials } & 70\end{array}$

$\begin{array}{ll}\text { e. Technological change } & 72\end{array}$

2. Cross-country data on human capital 78

$\begin{array}{ll}\text { a. Data on schooling } & 78\end{array}$

- Estimates of reliability ratios for different data sets $\quad 82$

b. Direct measures of skills and achievement $\quad 85$

3. Results of macroeconomic studies on human capital and growth 87

$\begin{array}{ll}\text { a. Ad-hoc growth equations } & 88\end{array}$

b. Results from structural convergence equations $\quad 94$

- Panel data specifications 99

$\begin{array}{ll}\text { c. Production function estimates and related specifications } & 101\end{array}$

- Rate effects and interaction with technological diffusion 102

$\begin{array}{ll}\text { d. Data quality and measurement error } & 106\end{array}$

$\begin{array}{ll}\text { e. Educational quality and test scores } & 109\end{array}$

- Can quality be purchased? 114

$\begin{array}{ll}\text { f. A plausible range of parameter estimates } & 115\end{array}$

4. Some human capital indicators for the EU and for candidate countries 119

5. Social capital: a survey of the theoretical and empirical literature 134

$\begin{array}{ll}\text { a. What is social capital? } & 136\end{array}$

b. Empirical evidence on social capital and aggregate performance 141

$\begin{array}{ll}\text { c. Social capital accumulation } & 146\end{array}$

$\begin{array}{ll}\text { d. Policy } & 150\end{array}$

References 153

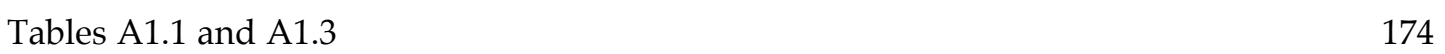




\section{EXECUTIVE SUMMARY}

This report examines the rationale for putting investment in human capital at the forefront of policies aimed at promoting economic growth and social cohesion, as is done in the strategy outlined in the Lisbon Summit for turning the EU into the most competitive and dynamic knowledge-based economy in the world. On the basis of a review of the relevant academic literature, we reach the following broad conclusions. First, investment in human capital contributes significantly to productivity growth. Second, there is clear evidence that human capital plays a key role in fostering technological change and diffusion. Third, human capital investment appears attractive relative to alternative assets, both from the individual and from the aggregate perspectives. Fourth, policies that raise the quantity and quality of the stock of human capital are compatible with increasing social cohesion. On the whole, our findings suggest that investment in people is both a crucial growth factor, particularly in the current context of rapid technological change, and a key instrument for enhancing social cohesion, and are therefore supportive of the policy strategy set out in Lisbon.

\section{A brief review of the academic literature}

There is a broad consensus in the academic literature that human capital is an important determinant of productivity and other economic outcomes, both at the individual and at the aggregate level, and that its role is particularly crucial in today's knowledge-driven economy. At the microeconomic level, there is very clear evidence that school attainment is a primary determinant of individual income and labour market status. Recent research suggests that an additional year of schooling increases wages at the individual level by around 6.5\% across European countries and that this effect can be as high as 9\% in EU members with less regulated labour markets where pay scales presumably reflect productivity more closely. There is also a robust relationship between individual wages and on-the-job training, with some estimates indicating that a year of training increases wages by as much as $5 \%$. These findings are supported by the empirical work that examines the connection between human capital and productivity at the firm level, which documents that high human capital workers increase productivity and are a direct source of innovation and long-term competitiveness. The literature also finds that the link between human capital and individual wages becomes stronger in times of rapid technological change.

At the macroeconomic level, there is evidence that the contribution of human capital to aggregate productivity growth is important, although considerable uncertainty remains about its exact magnitude because of various econometric problems that complicate the interpretation of the empirical results. What we consider to be the most plausible estimates 
in the literature suggest that, holding other things equal, an additional year of average school attainment increases the level of aggregate productivity by around $5 \%$ on impact and by a further 5\% in the long run. This second effect reflects the contribution of human capital to technological progress, i.e. to the development and adoption of new technologies and to the continued improvement of existing production processes. Some recent research also suggests that the quality of education may be just as important for productivity as its quantity, although further work is needed before we have reliable estimates of the size of the relevant effects.

Theoretical models of human capital and growth suggest that some of the benefits of a more educated labour force will typically "leak out" and generate macroeconomic benefits that cannot be appropriated in the form of higher earnings by those who undertake the relevant investment. These leakages are often called externalities, and they provide an important rationale for education subsidies and for other policies aimed at increasing human capital investment above its "free market" value. The literature we have reviewed provides some clear indications that such externalities do exist and that they are likely to be quite large. A key finding supporting this view is that macroeconometric estimates of the individual returns to schooling tend to be significantly larger than their microeconometric counterparts (when the latter are corrected in a way that makes the two variables directly comparable). Since macroeconomic estimates will capture all the induced output gains and microeconomic estimates only the part of such gains that can be directly appropriated by the individual undertaking the investment, the difference between these two figures can be interpreted as a measure of the size of the externalities arising from human capital. In our view, the most plausible sources of these externalities are the link between human capital and the rate of technological change that has already been mentioned, and the indirect effect of education on productivity and employment through the quality of institutions that may be considered a component of social capital.

Two important limitations of the existing literature are i) that it only provides precise quantitative estimates of some of the benefits from human capital and ii) that it has relied almost exclusively on measures of the quantity of formal schooling. Existing estimates of the returns to education do not generally take into account its direct consumption benefits, its pecuniary and non-pecuniary returns in leisure and home production (although there are indications that these can be quantitatively important), or the contribution of educational policy to social cohesion. As a result, estimates of the rate of return to education as those we will discuss below should probably be seen as providing a lower bound on the social benefits that would accrue from increased investment in human capital. Another reason why the social benefits to education are likely to exceed econometric estimates is the almost exclusive reliance of empirical work on data on years of formal schooling. This variable is used in practice for lack of better measures of the stock of human capital, i.e. of the skills and 
knowledge embodied in people that are useful in the production of goods, services and further knowledge. It is widely recognized, however, that school attainment will be at best an imperfect proxy for the true stock of human capital and that this generates a measurement error problem that will cause the statistical results to understate the strength of the connection between human capital and wages or productivity.

Human capital, growth and disparities in industrial countries

How important is human capital as a source of growth and cross-country differences in productivity? Working with the most plausible set of estimates of the relevant macroeconomic parameters, we estimate that, in the case of a "typical" OECD country, human capital accounts for 22\% of observed productivity growth over 1960-90 and for $45 \%$ of the productivity differential with the sample average in 1990. Roughly two thirds of each of these figures reflect the direct or immediate impact of schooling on the level of productivity, and the remaining third captures its contribution to technological progress.

Rates of return on schooling and some policy implications

Using the same set of estimates as in the previous exercise, we have calculated the private and social rates of return on schooling investment in a typical EU country and compared them with each other and with the rates of return on alternative assets. The objective of these comparisons has been to extract some conclusions about the optimality of observed investment patterns that may be of interest for policy formulation. The exercise is somewhat involved because it requires a series of adjustments to make the various rates of return fully comparable to each other. Its results, moreover, should be interpreted with caution because there is considerable uncertainty regarding the correct parameter values, the relevant rates of return on alternative assets, and the size of the benefits from education that are not captured by the existing empirical estimates.

With this in mind, we believe our results support two broad conclusions, which should be understood as applying to the average EU country.

First, a moderate increase in human capital investment is probably a good idea. The direct economic returns to schooling investment that are captured by macroeconometric studies are roughly comparable to those available from investment in physical capital. When a reasonable allowance is made for non-market returns to education and for its benefits for social cohesion, human capital becomes a rather attractive investment alternative from a social point of view.

Second, an across-the-board increase in general subsidies to formal education at the postcompulsory level is probably not necessary. This conclusion may be somewhat surprising in view of our emphasis on the importance of human capital externalities, but it must be kept in mind that education in the EU is already heavily subsidized and that compulsory schooling 
laws also tend to counteract such externalities and the resulting tendency for underinvestment in education. An additional factor that helps to close the gap between the private and social returns to education is that individuals and firms, unlike countries, have unlimited access at given prices to complementary inputs whose use will raise the return on human capital investment. These factors help explain our finding that, in spite of the existence of important externalities, the private rate of return relevant for individual schooling decisions compares quite favourably with the social rate of return on education and with those on competing assets available to households.

Hence, the economic incentives for investment in schooling are probably adequate. If a further increase in post-compulsory enrollments is considered desirable, it may be more important to eliminate implicit barriers impeding access to advanced programmes (such as liquidity constraints and lower levels of basic skills for individuals from disadvantaged backgrounds) through policies specifically targeted at these problems, rather than further decrease already low tuition charges that imply a large subsidy for relatively privileged groups. Indeed, higher tuition fees coupled with a well designed loan programme or with an increase in means-tested grants may be an efficient way to provide additional resources to increase the quality of post-secondary education while at the same time reducing the regressivity of its financing. Additional public funds, however, may be required at lower educational levels and for the expansion of adult training.

Our analysis offers some guidance in identifying the most productive uses of additional educational resources as well as changes in current practices that may increase efficiency. Since the main sources of non privately appropriable "excess returns" from human capital investment are likely to be this factor's complementarity with technology and its contribution to social cohesion, it may be argued that priority should be given to the following objectives. First, aim to give technology-related skills to a broad segment of the population and ensure an adequate supply of the technical and scientific personnel that is needed both for the development and for the adoption of new technologies. Second, support life-long learning in order to counteract the accelerated depreciation of skills in times of rapid technological change. Third, improve conditions for the accumulation of research-related human capital. Much of this human capital is generated as a by-product of research itself and human capital policies should therefore strengthen the link between tertiary education and both private and public research. Fourth, focus on improving the educational opportunities and the skills of individuals from disadvantaged backgrounds. This is likely to require a focus on early education in order to prevent the gradual build-up of handicaps arising from an unfavourable home environment. Some recent international studies suggest, moreover, that performance at the bottom of the student distribution can be significantly improved without lowering overall standards. Fifth, existing results on the close link between the quality of human capital and productivity suggest that an important contribution to growth may come from policies that 
raise student achievement. The existing literature suggests that progress in this area may come from improved curricula and teaching practices at least as much as from increased expenditure, although the latter may also be necessary.

\section{Conclusion}

On the whole, the evidence we have examined is consistent with the view that measures aimed at increasing the quantity and quality of the stock of human capital should be an important part of any growth-promoting policy package. This is certainly so in the case of the Lisbon strategy, which echoes many of the recommendations found in the literature. Implementation of the human capital policies outlined in successive EU summits appears especially important for those regions of the EU that are lagging behind in productivity and income per capita. It is important to recognize, however, that successful action requires a clear picture of the quantity and quality of regional human capital stocks in order to understand local needs and to identify those policies that are likely to be most effective. For example, it would be important to extend to the regional level recent studies that have tried to assess the skill levels of younger cohorts and of the workforce at large, and to support further research into the determinants of the performance of educational systems. These studies can be a useful input for the formulation of a systematic human resources policy that should be an important part of the EU's ongoing effort to increase regional cohesion. 


\section{Introduction}

Two years ago, the European Union set for itself the ambitious goal of becoming within a decade the most competitive and dynamic knowledge-based economy in the world. To achieve this goal, the Presidency Conclusions of the Lisbon Council outline a strategy for taking advantage of the growth and employment opportunities afforded by new technologies without sacrificing social cohesion. This strategy involves a broad set of measures designed to promote the development, adoption and use of new technologies through increased and more efficient investment in knowledge, skills and infrastructures, the development of an appropriate legal framework for innovation and for electronic transactions, increased deregulation and the promotion of competition in relevant sectors, and financial market reforms aimed at ensuring an adequate supply of risk capital. The document also underlines the need to improve employment policies and modernize social protection systems so as to promote social cohesion and gender equality while reducing disincentives and ensuring the sustainability of benefit levels.

Investment in people plays a key role in the Lisbon strategy because it is seen as both an essential growth factor and a key lever of social cohesion policy. Human capital is considered to be a crucial input for the development of new technologies and a necessary factor for their adoption and efficient use, but also a prerequisite for employability and an instrument for fighting social exclusion and gender discrimination. Accordingly, the Lisbon document calls for a substantial increase in per capita investment in human resources and sets out a long list of objectives and policy proposals that focus on four areas: the promotion of digital literacy, the increase in educational attainment beyond compulsory schooling, the development of a lifelong learning system geared to labour market needs, and the provision of an adequate supply of technical and R\&D personnel.

The present report examines the rationale for putting investment in human capital at the forefront of policies aimed at promoting economic growth and social cohesion, as is done in the Lisbon strategy. On the basis of a review of the relevant literature, we reach the following broad conclusions. First, investment in human capital contributes significantly to productivity growth. Second, there is clear evidence that human capital plays a key role in fostering technological change and diffusion. Third, human capital investment appears attractive relative to alternative assets, both from the individual and from the aggregate perspectives. Fourth, policies that raise the quantity and quality of the stock of human capital are compatible with increasing social cohesion. On the whole, our findings are therefore supportive of the policy strategy outlined in the Lisbon summit and of the premises that underlie it. They are also consistent with the important role attributed to human capital by a recent OECD (2001a) study that advances similar policy recommendations. 
The report is organized as follows. Section 2 defines human capital and discusses the reasons why it can be expected to be a key determinant of individual earnings and aggregate productivity, particularly in today's increasingly knowledge-based economy. Section 3 reviews the relevant evidence available in the academic literature. Microeconomic studies on the subject provide very clear evidence of a strong connection between human capital and labour market outcomes (including wages and employment probabilities) that makes education a key instrument for the preservation of social cohesion. At the macroeconomic level, the literature suggests that, while there is considerable uncertainty as to the exact magnitude of the growth effects of human capital, these are in any event sizable and justify a high level of investment in education and training. Section 4 briefly discusses the recent literature on social capital. In Section 5 we analyze the importance of human capital as a source of growth and income disparities in a sample of developed countries, and provide estimates of the private and social rates of return to schooling that are used to draw some tentative policy conclusions. Section 6 closes the main report with some general remarks on the implications of our findings for the formulation of EU policies. A series of appendices contain a more detailed review of the relevant literature and a set of human capital indicators for the EU and its candidate countries.

\section{Human capital and productivity in the knowledge economy}

Human capital is a broad and multifaceted concept encompassing many different types of investment in people. Health and nutrition are certainly an important aspect of such investment, particularly in developing countries where deficiencies in these respects may severely limit the population's ability to engage in productive activities. For the purposes of this report, however, the key aspect of human capital has to do with the knowledge and skills embodied in people and accumulated through schooling, training and experience that are useful in the production of goods, services and further knowledge.

To flesh out this broad definition, it may be useful to distinguish among the following three components of human capital:

- General skills related to basic language and quantitative literacy and, more broadly, to the ability to process information and use it in problem-solving and in learning. Basic language literacy can be defined as the ability to retrieve information from written texts and other materials and to encode information in similar media in an understandable and organized manner. Quantitative literacy involves the mastery of the rudiments of mathematics and the skills required to formulate problems in such a way that they can be solved through the application of the relevant techniques. These skills may be seen as partial aspects of a more general capacity for information processing and abstract reasoning that involves the ability to retrieve information from various sources and combine it with 
relevant knowledge to draw valid inferences and to generate useful hypotheses or generalizations that may offer insight into the solution of practical problems.

- Specific skills are those related to the operation of particular technologies or production processes. Examples include the ability to work with computer programmes of different degrees of complexity, to operate, maintain or repair a specific piece of machinery, and the techniques required in planting and harvesting.

- Technical and scientific knowledge, finally, refers to the mastery of specific bodies of organized knowledge and analytical techniques that may be of relevance in production or in the advance of technology, such as physics, architecture or the principles of logical circuit design.

There is a growing consensus that human capital is an important determinant of productivity, both at the individual and at the aggregate level, and that its role is particularly crucial in today's knowledge economy. Workers with greater problem-solving and communications abilities should perform better than their less skilled counterparts at any task that requires more than the routine application of physical labour and will also learn faster. Hence, skilled workers can be expected to be more productive than unskilled ones for any given production process, and should be able to operate more sophisticated technologies that place greater demands on their capacities. If skill does carry with it a greater ability to learn and produce new knowledge, moreover, a more educated labour force will also be able to achieve faster productivity growth, both through gradual improvements in existing production processes and through the adoption and development of more advanced technologies.

The available empirical evidence suggests that the importance of human capital as an input has grown over time as production processes have become increasingly knowledge intensive. Today, relatively few occupations involve only mechanical physical tasks, and a large and growing fraction of jobs either reduce to the processing of information or require the application of specialized knowledge and skills to the production of increasingly sophisticated goods and services. ${ }^{1}$ This is also true in relation to the production of the applied knowledge that underlies technical progress, which has gradually become more reliant on explicit R\&D activities, more closely intertwined with formal science and, as a result, increasingly skill intensive.

The rapid improvement and spread of information and communications technologies (ICT) in recent years is an important event that has significantly contributed to the development of the knowledge economy and to the acceleration of the secular trends that underlie the rising

\footnotetext{
${ }^{1} \mathrm{~A}$ recent OECD (1999) study finds that over half of the combined output of its member countries is produced in knowledge-intensive industries. These include not only advanced-technology manufacturing sectors such as ICT, but also intensive users of new technologies and of skilled labour, such as finance, insurance and communications services.
} 
significance of human capital. ${ }^{2}$ The implications of ICT are far reaching because these are general-purpose technologies with potential applications in many sectors and because they have greatly increased human capacity to store, access and process information rapidly and at low cost. Hence, advances in ICT are likely to gradually spread to user sectors, making for rapid technological and organizational change throughout the economy, and can be expected to contribute to the acceleration of technical progress and to its diffusion by providing researchers with powerful new tools and practically instant worldwide access to information. ICT is also likely to increase competition in many markets by giving firms the possibility to search for customers and suppliers all over the globe, and will further erode locational rents and advantages by greatly reducing transport costs for knowledge and information outputs. To use a currently fashionable term, ICT can contribute significantly to the process of globalization (or to increased global competition) by making the world effectively smaller in many ways. This will increase competitive pressures on national economies, and make it particularly crucial for them to have access to an adequate supply of skilled labour in order to stay ahead in the technological race and to have access to the potential benefits of the new technologies.

\section{Empirical evidence on human capital and productivity}

The hypothesis that human capital is a key determinant of productivity has received considerable attention in the academic literature. Labour economists have long been concerned with the impact of schooling and skills on individual wages and other labour market outcomes. Building on this work, macroeconomists have been using growth accounting techniques to analyze the contribution of education to aggregate economic growth since the 1960s. Research in this second area has received a new impulse in recent years with the development of a new generation of theoretical models that attribute to the accumulation of knowledge and skills a central role in the process of economic development and with the construction of broad cross-country data sets that can be used in the empirical analysis of the determinants of economic growth. In this section we will review the relevant literature in both areas of research with the objective of determining to what extent the available empirical evidence supports the hypotheses laid out in the previous section about the micro and macroeconomic links between human capital and productivity. ${ }^{3}$

Before getting into the specifics of each line of work, it is important to highlight some of the similarities, differences and interconnections between them. In both branches of the literature, the typical empirical exercise involves the use of statistical techniques (generally regression analysis) to try to determine how an increase in educational attainment will affect

\footnotetext{
2 See OECD (2001a) for a more detailed analysis of some of the implications of the "new economy."

3 There are a number of excellent surveys in the literature that cover many of the issues we will discuss. Among others, see Griliches (1997), Card (1999) and Temple (2001).
} 
individual earnings or average productivity at the aggregate level. Hence, years of schooling is the measure of the stock of human capital most commonly used in both micro and macroeconomic analyses. Sometimes this choice reflects a direct interest on the impact of schooling per se, but this variable is often used for lack of better measures of human capital. It is widely recognized that school attainment will be at best an imperfect proxy for the true stock of human capital and that this generates a measurement error problem that will cause the statistical results to underestate the strength of the connection between human capital and wages or productivity. It is expected, however, that (since many of the relevant skills are acquired through formal schooling) the correlation between years of education and human capital will be sufficiently high for analyses that use the former as a proxy for the latter to yield some useful information. ${ }^{4}$

In both the micro and the macroeconomic literatures, the theoretical framework that underlies the empirical analysis assumes a stable technical relationship between inputs and output that can be described by a production function. In the microeconomic case, the further assumption is commonly made that observed wages reflect marginal productivities. In both cases, the objective of the analysis is to obtain estimates of a technical coefficient measuring the contribution of schooling to productivity. This parameter turns out to be an important determinant of the return to investment in schooling and is often interpreted directly as such (even though some model-specific adjustments are typically required to obtain the exact rate of return). ${ }^{5}$

Comparisons of micro and macroeconometric estimates of the returns to education are potentially of great interest because discrepancies between them can alert us of the existence of externalities that drive a wedge between the private and public returns to schooling and may call for corrective policy action. For instance, if the productivity of each worker increases with average education at the aggregate level as well as with his own school attainment, the first of these effects will constitute an externality and will generate a tendency for underinvestment in education because individuals will fail to take into account the indirect social benefits that can arise from their schooling choices. In this context, microeconometric estimates of wage equations with individual cross-section data for a given country will only pick up the own-education effects of schooling (because the indirect aggregate effect does not vary across individuals within a given country), whereas macroeconometric estimates with cross-country data should also capture the externality. Hence, the finding that the return to education is higher at the aggregate than at the individual level may be interpreted as evidence of the existence of positive externalities that may justify public subsidies designed to raise investment in education to its socially

\footnotetext{
4 Some recent studies that attempt to measure skills directly suggest that this assumption is broadly correct, but also that things other than formal education contribute to the development and maintenance of skills. See OECD and Statistics Canada (2000) and section 2 of the Appendix to this report.

5 See section 5 c below.
} 
optimal level. Conversely, the reverse finding may be interpreted as providing some support for signalling or screening theories in which education does not necessarily increase productivity per se but may still increase wages because it serves as a signal for ability (i.e. allows employers to identify high-ability individuals) or as a credential for access to privileged jobs.

Such comparisons have to be made with extreme care, however, because, even in the absence of externalities, micro and macroeconomic estimates of the returns to schooling can differ for a number of reasons. A first reason, to which we will return below, is that there are statistical problems (biases related to the omission of relevant variables, errors in the measurement of years of schooling and reverse causation from income to the demand for education) that may affect the two sets of estimates to different extents. Second, it must be kept in mind that micro and macroeconomic estimates measure different things. Even if both sets of coefficients do indeed reflect the marginal productivity of schooling, microeconometric estimates will tell us what happens to the earnings of an individual as his schooling rises, holding constant factor prices and the economy-wide average level of education, whereas macroeconometric estimates will capture the effects of changes in aggregate average schooling on labour productivity holding the aggregate stock of physical capital constant. Hence, the coefficients of micro and macro studies are not directly comparable and have to be adjusted (in a way that will depend on the chosen econometric specifications) before valid inferences can be drawn about their relative values. ${ }^{6}$ Third, it may be that wage scales do not exactly reflect marginal productivities because of distortions introduced by labour market institutions. In societies with a high aversion to inequality, for instance, collective bargaining may lead to relatively flat payscales ("wage compression") that are likely to make the estimated private return to education fall below its contribution to productivity. Some allowance must be made for this possibility when comparing microeconometric estimates of the gross return to schooling across countries or with their macroeconometric counterparts.

\section{a. Human capital and labour market outcomes: microeconomic evidence}

Labour economists often distinguish between human capital accumulated during three distinct phases of life: early human capital, mainly acquired at home, human capital acquired through formal education, and human capital accumulated through on-the-job training. Most of the work of empirical researchers has concentrated on the labour market consequences of human capital acquired through formal education, mainly because it is the component of human capital that is easiest to measure. In this section, we will briefly review and summarize the main conclusions regarding the labour market effects of formal education.

\footnotetext{
6 Essentially, the adjustment is needed to hold physical capital constant in the microeconomic estimates. Under reasonable assumptions, the required correction involves reducing microeconometric estimates by around one third. See de la Fuente (2002a).
} 
We will also touch on the economic consequences of on-the-job training, both for the individual obtaining the training and for the firm doing the training.

The three basic conclusions emerging from the large body of empirical work on the labour market consequences of formal education is that higher levels of education are accompanied by higher wages, lower unemployment probabilities, and higher labour force participation rates. Most of the work has been done on the link between schooling and wages. This is because the resulting wage increase is the most important economic consequence of higher levels of formal education. Moreover, as we mentioned earlier, wages are often seen as reflecting marginal labour productivity, which implies that the link between formal schooling and wages can be used to analyze the productivity effects of formal schooling.

\section{i. Methodological issues in estimating the effect of formal schooling on wages}

Empirical work on the effect of formal schooling on wages estimates the percentage increase in wages implied by additional schooling. The main difficulty of estimating this effect correctly is that individuals with high and low levels of schooling differ in many respects, not just their schooling levels. Examples of such characteristics are family background and ability. To the extent that these other differences are observable to researchers, they can be taken into account directly in the statistical analysis. Standard methods, i.e. least-squares estimation, can then be used to identify the percentage increase in wages implied by additional formal education, holding other observable characteristics like family background constant. But some characteristics of individuals are difficult to observe. For example, there is often little information about the ability of individuals. This raises difficulties, as it seems likely in some contexts that ability is positively correlated with both schooling and wages. Omitting ability from the analysis and using least squares estimation will therefore tend to attribute some of the wage-increase explained by ability to education. Hence, the effect of schooling on wages would be overstated. Another problem in estimating the percentage increase in wages implied by additional formal education is that individual schooling is often reported with error. As we already mentioned, measurement error alone implies that least-squares results understate the effect of formal schooling on wages.

Empirical researchers have taken two different routes in trying to resolve the difficulties raised by unobservable determinants of wages and schooling as well as mismeasurement of individual schooling. The first route consists of estimating the effect of schooling on wages using data on (identical) twins. The basic idea is that twins are more similar in many dimensions than two randomly chosen individuals and omitted determinants of wages and schooling should therefore be less of a problem in estimating the effect of formal schooling on wages using least-squares techniques. The second route relies on a non-standard statistical technique called instrumental-variable (IV) estimation. The IV approach requires an additional variable, a so-called instrument, that affects years of schooling but is not 
correlated with omitted determinants of wages or the measurement-error of individual schooling. Using this instrument, the researcher first obtains an estimate of the effect of the instrument on schooling and then on wages. The instrumental-variable estimate of the effect of formal schooling on wages is obtained by dividing the latter by the former. Instruments used in practice include institutional changes affecting school leaving age or changes in tuition costs.

\section{Box 1: Mincerian wage regressions and the "return" to schooling}

Following Mincer (1974), the specification used to estimate the effect of individual schooling on individual wages has been

(1) $\ln W_{i}=\alpha+\theta S_{i}+\gamma e_{i}+\mu e_{i}^{2}+\phi X_{i}+u_{i}$

where $W$ is the (hourly) wage, $S$ schooling, $e$ experience, $X$ a set of other individual characteristics, and $u$ the variation in log-wages not captured by the right-hand-side variables. The parameter $\theta$ measures the percentage-increase in wages associated with an additional year of schooling and is assumed to be independent of the level of schooling (although this specification seems quite restrictive a priori, it has been shown to fit the data well in many developed countries (e.g. Heckman, Lochner, and Todd (2001)). Mincer shows that under certain conditions, which include that there are no direct costs of education, $\theta$ can be interpreted as the proper private return to schooling. This is why estimates of $\theta$ are often referred to as the "return to schooling." Generally, however, $\theta$ will not be equal to the proper return to schooling for several reasons, including the fact that there is a direct cost of education (see Box 5 below). This is why we will refer to $\theta$ as the Mincerian return to schoolinig (sometimes $\theta$ is also referred to as the schooling wage-premium or as the gross return to schooling).

\section{ii. Review of the estimates obtained with different methodologies}

There are many circumstances where the only estimates of the Mincerian return to schooling available are obtained using standard statistical techniques. It is therefore important to understand whether estimates of the Mincerian return to schooling obtained with least-squares techniques are systematically different from estimates relying on twins or an IV approach. The growing literature on this issue suggests that, overall, the estimates obtained using twins or an IV approach are somewhat greater than estimates using leastsquares techniques. The question of whether these differences are significant is analyzed in Ashenfelter, Harmon and Oosterbeek (1999). Examining the results of several studies in the US and seven non-US countries between 1974 and 1995, they find that IV estimates and twin studies estimates exceed least-squares estimates by 3.1 and 1.6 percentage points. This difference decreases, however, once they control for the fact that studies producing no interesting results --insignificant difference between the IV and the least-squares estimates for example-- are less likely to be published. The corrected differences are 1.8 and 0.9 percentage points respectively. 


\section{iii. Trends of the Mincerian return to schooling over time}

It is well documented that the Mincerian return to schooling in the US decreased during the 1970s and increased during the 1980s, generating a U-shaped time pattern of educational wage-differentials. There is a consensus that these changes may be interpreted as outcomes of shifts in the supply and demand for human capital. The basic idea is that the increase in the supply of high human capital workers dominated demand growth during the 1970s, reducing the Mincerian return to schooling. During the 1980s, however, the increase in the demand for high human capital workers dominated supply growth, raising the schooling wage-premium (e.g. Katz and Murphy (1992)). The growth in the demand for human capital is commonly attributed to technological change.

The Mincerian return to schooling in Europe as a whole followed a U-shaped time-pattern similar to the US. In the 1960s, the Mincerian return to schooling was higher than in the 1970s. In the 1980s, the Mincerian return to schooling dropped further, but started to rise again during the 1990s. Denny, Harmon, and Lydon (2001) confirm this pattern by reviewing a large number of studies on the Mincerian return to schooling for different European countries and time-periods. Comparing the US with Europe, they show that the Mincerian return to schooling in Europe exceeded the return in the US in the early 1960s. In the course of the 1960s and 1970s, estimates of the Mincerian return to schooling in Europe and in the US fell at a similar rate. But the US estimates reached their minimum at the end of the 1970s, while European estimates continued to decline until the mid 1980s. The subsequent increase in estimates of the Mincerian return to schooling was much more pronounced in the United States. By 1997 the Mincerian return to schooling in the US was about 3 percentage points higher than in Europe. It is important to keep in mind, however, that while the overall pattern of change in Europe was similar to the US, behaviour across European countries differed widely.

\section{iv. Differences across European countries}

The Mincerian return to schooling varies considerably across European countries. For example, Harmon, Walker and Westergaard-Nielsen (2001) find that the Mincerian return to schooling is lowest in Scandinavian countries (around 4 percent in Norway, Sweden, and Denmark; Finland is an exception) and highest in Ireland and the UK (around 12 percent). Reviewing a large number of studies, they find an average Mincerian return to schooling of around 6.5 percent in Europe. Similar evidence is provided by Denny, Harmon, and Lydon (2001), who estimate the Mincerian return to schooling using homogenized data for different European countries. They find large differences, with Norway at the bottom and Ireland and the UK at the top. But there remains considerable uncertainty on how European countries rank in the schooling wage-premium (European Investment Bank, 2001)). 


\section{v. Female-male wage differentials}

In most industrialised countries the gender wage-differential decreased during the last decades. This is partly explained by the fact that differences in years of schooling among male and female full-time workers have largely disappeared (e.g. Blau and Kahn (1997), Harkness (1996)). Not only schooling of women, but also female labour force participation and consequently women's accumulated labour force experience has increased. These changes in experience seem to have been even more important in closing the gender wage-differential than the increase in years of education. Today it is not the amount of schooling, but rather differences in what men and women study as well as differences in aptitudes and achievement scores across subjects through which schooling appears to affect gender wage-differentials. For example, recent results of the Programme for International Student Assessment (PISA; OECD (2001)) indicate that while males are likely to under-perform in reading, women seem to have a disadvantage in mathematics.

Less working hours and fewer years in the labour market lead according to standard human capital theory to less investment in general human capital. Furthermore, women have traditionally higher turnover than men. Expected job-separation may discourage investment in employer specific human capital. Empirical evidence supports the notion that women are less likely to receive training (e.g. Lynch (1992)). Furthermore, men receive a higher training duration and are more likely to have jobs requiring longer training periods (e.g. Altonji and Spletzer (1991), Barron, Black, and Lowenstein (1993)).

There has been a growing amount of research on the impact of part-time and temporary work on the wages of women. Women are heavily over-represented in part-time and temporary jobs, which typically pay lower hourly wages than full-time or permanent jobs. While differences in schooling among male and female full-time workers have disappeared completely for younger cohorts, part-time working women continue to be less qualified than full-time working men or women. As a result, the relative earnings position of women working part-time has changed little over the last decades (e.g. Harkness (1996)).

There is considerable evidence that the Mincerian return to schooling is greater for women than men in European countries. For example, Harmon, Walker and Westergaard-Nielsen (2001) find that the effect of schooling on female wages exceeds the effect on male wages by 5 percentage points in Ireland and by 2 or more percentage points in Italy, (West) Germany, Greece, and the UK. Denny, Harmon, and Lydon (2001) argue that the differential is greater in countries with lower female labour force participation.

\section{vi. Effects of education on unemployment and labour force participation}

Formal education affects life-time earnings also through the probability of unemployment. For example, according to a study of the European Investment Bank (Heinrich and Hildebrand, 2001), male university graduates have lower unemployment rates than 
Figure 1: Unemployment by educational attainment level

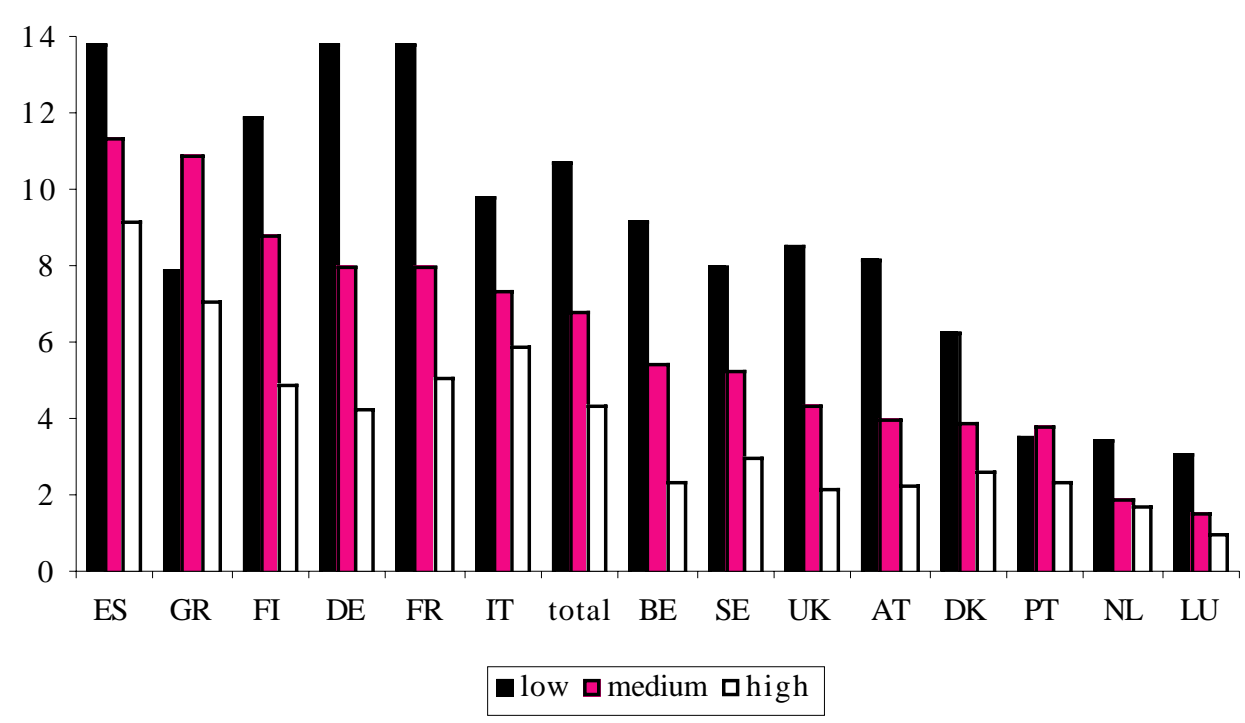

Figure 2: Labour force participation by educational attainment level

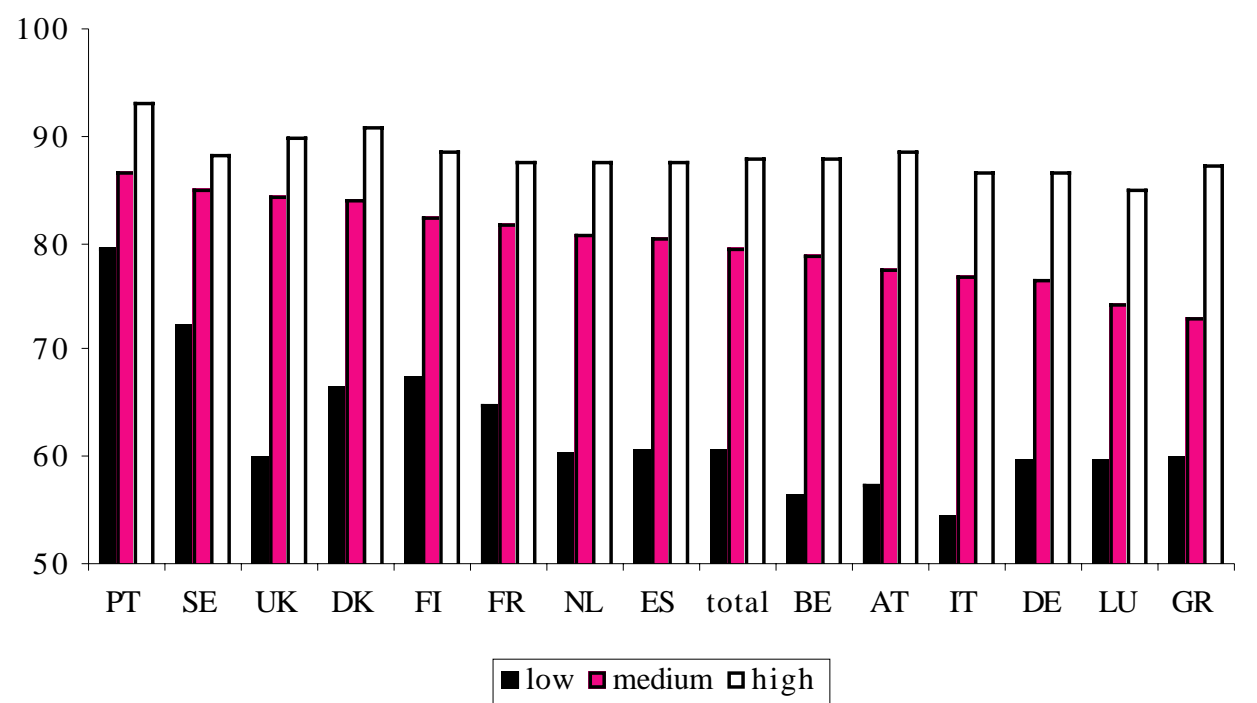

- Source: Eurostat, Labour Force Survey, Spring 2000.

- The data refer to the population aged 25 to 64 . Low attainment includes primary and lower secondary education and elementary vocational training (ISCED levels 1 and 2); medium refers to higher secondary education and vocational programmes (ISCED 3 and 4); and high to post-secondary training (ISCED level 5 or higher). There is no data for Ireland.

- Key: $\mathrm{PT}=$ Portugal; $\mathrm{SE}=$ Sweden; $\mathrm{UK}=$ United Kingdom; $\mathrm{DK}=$ Denmark; FI $=$ Finland; FR $=$ France; $\mathrm{NL}=$ Netherlands; ES = Spain; total = entire sample; BE = Belgium; AT = Austria; IT = Italy; DE = Germany; LU = Luxembourg and GR = Greece.

workers with less education in all European countries except Denmark. Moreover, the differences are sometimes very large. In Ireland for example, the unemployment rate among men with basic education is five times the unemployment rate of male university graduates. In Finland, male workers with a basic education are twice as likely to be unemployment as those with an upper-level secondary education. The pattern among women is more complex. 
Still, in the majority of European countries, the unemployment rate among women falls with their education levels.

Education also affects labour force participation. For example, according to the EIB study, Belgian women with a university education are 42 percent more likely to participate in the labour force than those with a basic education; similarly, Dutch women with an uppersecondary education are 22 percent more likely to participate in the labour force than those with a basic education. The only exception to this rule seems to be the UK, where women with a secondary education are less likely to participate in the labour force than those with a basic education.

Recent data from Eurostat also confirms the existence of a strong connection between educational achievement and employment and participation rates. As illustrated in Figures 1 and 2, unemployment rates decrease and participation rates rise as we move from low to high educational attainment levels in practically all EU countries (with Greece and Portugal being partial exceptions in terms of the unemployment rate, which is highest in these countries for intermediate attainment levels). For the sample as a whole, moving from low to intermediate attainment reduces the unemployment rate by 3.95 points and increases the labour force participation rate by 18.8 points. When we consider the difference between the highest and the lowest attainment categories, these figures increase to 6.33 and 27.2 points respectively.

\section{vii. The rate of return to education}

So far we have only dealt with the Mincerian return to schooling. Now we turn to the proper return to schooling, i.e. to the return on the resources invested in education. ${ }^{7}$ The literature distinguishes two rates of returns, the private rate of return and the social rate of return. The private rate of return relates the resources invested by those obtaining the education (the opportunity cost as well as direct costs) to the private benefits of education. The social return includes the public cost of education in these calculations. Notice that while the social return accounts for the total (private and public) resources invested in education, it relates these resources to the private benefits of education only (i.e. it does not account for possible externalities). Ideally, the social rate of return to education would relate all resources invested in education to all benefits of education.

According to a recent OECD study (OECD (2001b)), the private return of a tertiary education for men in Europe averages more than 12 percent. The country with the highest return is the UK (17.3 percent), followed by Denmark (13.9 percent) and France (12.2 percent). Italy (6.5 percent) is at the bottom of the ranking. The average rate of return to uppersecondary education for men is also around 12 percent, with the UK (15.1 percent) and France (14.8 percent) at the top of the ranking and Sweden (6.4 percent) and the Netherlands (7.9)

\footnotetext{
7 See section 5.c below for a more detailed discussion of the calculation of the proper rate of return on schooling.
} 
percent at the bottom. The average rate of return for women is similar when it comes to tertiary education, but the rankings differ. The country with the highest private return of a tertiary education for women is the UK (15.2 percent), followed by the Netherlands (12.3 percent) and France (11.7 percent). The average private return to an upper-secondary education for women in Europe is around 11 percent, with France (19.2 percent) and Denmark (10.5 percent) at the top and Germany (6.9 percent) at the bottom (data for the UK was not available in this case).

The social rates of return are generally somewhat lower than the private ones. For example, the social rate of return of a tertiary education for men is on average around 2 percentage points lower than the private return (the outliers are Denmark and Sweden where it is 4 or more percentage points below). For women, the gap between the social and the private return is similar (but the Netherlands now join the outliers, with the private return exceeding the social return by 6 percentage points). Comparing the social and private rates of return of upper-secondary education yields a very similar pattern.

It should be kept in mind that these rates of return most likely are lower bounds for two reasons. First, these returns are based on least-squares estimates of the Mincerian return to schooling. We have already seen that estimates of the effect of education on wages using more sophisticated techniques yield effects that are 1 to 2 percentage points higher on average. Second, the social rates of return do not include social benefits in excess of private benefits of education (e.g. Arias and McMahon (1999)). We will argue later that, although there is considerable uncertainty regarding these benefits, they are potentially large.

\section{viii. On-the-job training, human capital, and productivity at the firm level}

The literature on on-the-job training has examined three basic questions. First, does onthe-job training increase productivity and profitability at the firm level? Does on-the-job training increase wages? And who obtains on-the-job training?

There is clear evidence that on-the-job training increases productivity at the firm level (e.g. Bartel (1991), Lynch and Black (1995)). Moreover, on-the job-training is also a source of innovation and therefore long-term competitiveness of firms (e.g. Blundell, Dearden, Meghir, and Sianesi (1999)). When it comes to firm profitability, the evidence is mixed, with some studies arguing that profitability increases and others that profitability is unaffected. ${ }^{8}$ This is not surprising, as the theoretical link between productivity growth at the firm level and profitability is complex.

Individual workers receiving on-the-job training have consistently been found to earn higher wages (e.g. Blundell, Dearden, and Meghir). For example, individuals undertaking

\footnotetext{
8 For example, Bassi, Harrison, Ludwig and McMurrer (2001) show that firms investing in training pay extra-normal returns to shareholders. They also emphasize, however, that while this correlation is consistent with a causal effect, it may also reflect that training is a leading indicator of other factor translating into high profitability.
} 
on-the-job vocational training in the UK earn on average 5 percent more than individuals who have not undertaken such training.

Regarding the question of who obtains on-the-job training, the evidence indicates that on average training is given to workers with higher ability and more education. Hence, the three components of human capital (early human capital, formal education, and on-the-job training) tend to be complementary over the life-cycle of workers (e.g. Lynch and Black (1995)). Still, on-the-job training of workers with low qualifications has large effects on their productivity (e.g. Blundell, Dearden, Meghir, and Sianesi (1999)). There is also evidence that training is especially productive in a rapidly changing technological environments (e.g. Bartel and Sicherman (1993)).

Empirical work at the firm level also indicates a clear link between human capital and productivity at the firm level (e.g. Lynch and Black (1995), Blundell, Dearden, Meghir, and Sianesi (1999)). Moreover, high human capital workers are a direct source of innovation and hence long-term competitiveness. This is not too surprising of course as firms employ more expensive, high human capital workers only if their productivity offsets the higher cost.

\section{ix. Technological change and the effect of human capital on wages}

The most important explanation suggested for the positive link between wages and schooling is that education enables individuals to adopt, implement, or work with more advanced technologies. After briefly summarizing the main theories, we review empirical evidence on the association between technology on the one hand and the demand for human capital, wages and employment on the other. We restrict ourselves to the analysis of studies using direct measures of technology.

The last decades witnessed major technological changes, such as the rapid spread of computers, the expansion of computer-assisted production techniques and robots, and new information and communications technologies. How do these changes affect the relative demand for high human capital workers? There exist basically two hypotheses, which try to explain the relation between the relative demand for high human capital workers and technological change. The first hypothesis relates the rate of technological change and the demand for high human capital workers. If highly educated workers have a comparative advantage in adjusting to new technologies and implementing them, then the spread of these new technologies is likely to increase the demand for high human capital workers relative to low human capital workers. If the increase in the demand for high human capital workers outstrips the increase in supply, the Mincerian return to schooling increases. The second hypothesis claims that new technologies introduced in the last decades are skill biased, i.e. replace labour intensive tasks and are complementary to high human capital workers. Hence, the transition to new technologies results in an increase in the demand for human capital holding output and relative prices constant. 
There exists clear evidence that more computerized or R\&D intensive industries increased their demand for college-educated workers at a faster rate in the 1980s. For example, Machin and Van Reenen (1998), using R\&D intensity at the industry level as a measure of technology, provide evidence for skill-biased technological change in Denmark, France, Germany, Japan, Sweden and the UK. Berman, Bound and Griliches (1994) and Autor, Katz and Krueger (1996) document a strong positive correlation between the level of computer investment and the demand for human capital at the industry level. Using a cross-section of US plants, Doms, Dunne and Troske (1997) also come to the conclusion that better technologies are accompanied by higher demand for human capital. Looking at the same plants at different point in times, however, reveals that plants that adopt new technologies have a higher proportion of high human capital workers even before the adoption of new technologies. Human capital is therefore a pre-requisite for the implementation of new technologies. Aguirrebriria and Alonso-Borrego (1997), Dueguet and Greenan (1997), and Haskel and Heden (1997) come to similar conclusions using data on Spanish, French, and British plants.

While there exists evidence that technological change affects the relative demand for high human capital workers, only a few studies examine the exact mechanisms. Some authors conjecture that organizational change might play a key role (e.g. Dunne, Haltiwanger and Troske (1996), Machin and van Reenen (1998)). In most industrialized countries, there has been a trend towards less hierarchy and more flexible organizational forms, as workers are given more autonomy and perform a wider range of tasks. Caroli and Van Reenen (1999) use a panel of British and French plants in order to investigate whether organizational changes such as the decentralization of authority, delayering of managerial functions, and increased multitasking affects the demand for human capital. They find these changes tend to reduce the demand for low human capital workers and lead to greater productivity growth (especially in establishments with higher average levels of human capital).

The increase in the Mincerian return to schooling and the rise in wage-inequality in the US during the 1980s, combined with the widespread notion that technological change may be the driving force behind it, triggered a large number of studies on the link between wages and technological change. The consensus emerging from these studies is that the increase in the schooling wage-premium and the rise in wage-inequality are driven by technological change. For example, Mincer (1993) shows that relative earnings of college graduates in the US increased with the aggregate R\&D intensity between 1963 and 1987. Krueger (1993) argues that the wage structure has been changed by the widespread introduction of computers. And Allen (1998) finds that the schooling wage-premium between 1979 and 1989 rose most in industries with a greater $\mathrm{R} \& \mathrm{D}$ and high-tech capital.

At the firm and industry level there appears to be no robust positive correlation between technological change and wages of high human capital workers (e.g. DiNardo and Pischke (1997), Entorf and Kramarz (1997)). This is not too surprising, however, as skill-biased 
productivity growth at the level of a single firm or industry will translate into increased demand for human capital but not into wages in a competitive environment.

\section{$x$. Technological change and employment}

To understand the theoretical effect of technological change on employment, assume that a firm decides to implement a computer-assisted production process. The implementation of this new process allows the firm to produce the same amount of output with a lower level of employment, generating a negative employment effect. This translates into a cost reduction and lower prices. Lower prices may translate into larger demand and therefore output, generating a positive employment effect. Whether employment is higher before or after the adoption of the new technology depends on a variety of factors. The positive employment effect tends to increase with competition in the sector experiencing technological change, the extent of economies of scale, and the elasticity of demand. These considerations imply that the relationship between technological change and employment at the firm and industry level is a priori unclear. Empirical studies on the relationship between employment and technology have been relatively scarce. Analysing manufacturing industries in the OECD, Blechinger, Kleinknecht, Licht and Pfeiffer (1998) show that industries with higher R\&D intensity expanded more quickly. Firm level studies provide a wide variety of results from different countries however. It appears that product innovation has a positive effect on employment growth in Germany but a negative effect in France (e.g. Entorf and Pohlmeier (1990), Greenan and Guellac (2000)). Evidence concerning process innovations is also mixed (e.g. Blanchflower and Burgess (1998), Blechinger et al. (1998)).

\section{xi. Non-market returns to schooling}

So far we have only discussed the return to education related to improved labour market performance. There is a large literature identifying additional non-market returns for individuals and families (e.g. McMahon (1998)). The main component of these additional returns is usually taken to be the positive effect of education on own health and on the health of families headed by better educated individuals. For example, better educated men have a lower risk of death from heart disease, and children of better educated women have lower mortality rates (e.g. Feldman et al. (1989)). Some studies argue that health benefits can add up to 40 percent to the labour market return of schooling (e.g. Wolfe and Zuvekas (1997)). Another important non-market component of the return to schooling is the efficiency of home production, including the management of household finances and the education of children. For example, households headed by more educated individuals achieve higher returns on financial assets and the children of better educated parents stay longer and do better in school (e.g. Solomon (1975), Angrist and Levy (1996)). Moreover, better educated individuals are more efficient learners later in life (e.g. Mincer (1993)). These non-market returns imply that 
the private and social labour market returns to human capital should be seen as lower bounds when making investment decisions.

\section{b. Human capital and growth: macroeconomic evidence}

This section surveys the macroeconomic evidence on the growth effects of education. After briefly reviewing the role of human capital in recent theories of growth, we discuss the specifications most commonly used in empirical work in this area, some econometric issues that arise in their estimation, and the main results of the literature. A more detailed literature review is contained in section 3 of the Appendix to this report. ${ }^{9}$

\section{i. Human capital in growth theory}

One of the most distinctive features of the "new" theories of growth developed in recent years has been the broadening of the relevant concept of capital. While traditional neoclassical models focused almost exclusively on the accumulation of physical capital (equipment and structures), more recent contributions have attributed increasing importance to the accumulation of human capital and productive knowledge and to the interaction between these two factors. 10

Theoretical models of human capital and growth are built around the hypothesis discussed in section 2, namely that knowledge and skills embodied in humans directly raise productivity and increase an economy's ability to develop and to adopt new technologies. In order to explore its implications and open the way for its empirical testing, this basic hypothesis is generally formalized in one of two (not mutually exclusive) ways. The simplest one involves introducing the stock of human capital (which will be denoted by $H$ throughout this report) as an additional input in an otherwise standard production function linking aggregate output to the stocks of productive inputs (generally employment and physical capital) and to an index of technical efficiency or total factor productivity (TFP). The second possibility is to include $H$ in the model as a determinant of the rate of technological progress (i.e. the rate of growth of TFP). This involves specifying a technical progress function that may include as additional arguments variables related to R\&D investment and the gap between each country and the world technological frontier. We will refer to the first of these links between human capital and productivity as level effects (because the stock of human capital has a direct impact on the level of output) and to the second one as rate effects (because $H$ affects the growth rate of output through TFP). As will be emphasized later, the distinction between these two types of effects, while conceptually clear, is often less sharp in

\footnotetext{
9 This section and parts of section 5 are based on de la Fuente (2002a).

10 See especially Lucas (1988), Romer (1989), Azariadis and Drazen (1990), Mankiw, Romer and Weil (1992) and Jones (1996). Some recent studies in this literature draw on earlier work by Uzawa (1965), Nelson and Phelps (1969) and Welch (1970) among others.
} 
practice than may appear from the preceding discussion, particularly in models that allow for the diffusion of technology across countries.

Some recent theoretical models also suggest that the accumulation of human capital may give rise to important externalities, as some of the benefits of a more educated labour force will typically "leak out" and generate benefits that cannot be appropriated by those who undertake the relevant investment in the form of higher earnings, thereby driving a wedge between the relevant private and social rates of return. Lucas (1988), for example, suggests that the average stock of human capital at the economy-wide level increases productivity at the firm level holding the firm's own stock of human capital constant. It is also commonly assumed that the rate effects of human capital through the technical progress function include a large externality component because it is difficult to appropriate privately the full economic value of new ideas. Azariadis and Drazen (1990), and implicitly Lucas (1988) as well, stress that younger cohorts are likely to benefit from the knowledge and skills accumulated by their elders, thus generating potentially important intergenerational externalities that operate both at home and in school. The literature also suggests that human capital can generate more diffuse "civic" externalities, as an increase in the educational level of the population may help reduce crime rates or contribute to the development of more effective institutions.

\section{ii. Empirical formulations}

Empirical studies of the productivity effects of human capital (or more broadly, of the determinants of economic growth) have followed one of two alternative approaches. The first one involves the specification and estimation of an ad-hoc equation relating growth in total or per capita output to a set of variables that are thought to be relevant on the basis of informal theoretical considerations. The second approach is based on the estimation of a structural relation between the level of output or its growth rate and the relevant explanatory variables that is derived from an explicit theoretical model built around an aggregate production function and, possibly, a second function that describes the determinants of technical progress.

This basic framework for the "structural" analysis of the determinants of growth can give rise to a large number of empirical specifications. As explained in greater detail in Box 2, the production function can be estimated directly with the relevant variables expressed in levels or in growth rates when reliable data are available for the stocks of all the relevant production inputs. Alternatively, its parameters can be recovered from other specifications (convergence and steady state equations) that are designed for estimation when only data on investment flows (rather than factor stocks) are available. These specifications can be derived from production functions by replacing factor stocks or their growth rates by convenient approximations constructed using observed investment rates. 


\section{Box 2: Some commonly used growth specifications}

Many studies of the determinants of growth assume an aggregate Cobb-Douglas production function of the form

$$
\text { (1) } Y_{i t}=A_{i t} K_{i t}{ }^{\alpha_{k}} H_{i t}{ }^{\alpha_{h}} L_{i t} \alpha_{l}
$$

where $Y_{i t}$ denotes the aggregate output of country $i$ at time $t, L_{i t}$ is the level of employment, $K_{i t}$ the stock of physical capital, $H_{\mathrm{i} t}$ the average stock of human capital per worker, and $A_{i t}$ an index of technical efficiency or total factor productivity (TFP) which summarizes the current state of the technology and, possibly, omitted factors such as geographical location, climate, institutions and endowments of natural resources. The coefficients $\alpha_{i}$ (with $i=k, h, l$ ) measure the elasticity of output with respect to the stocks of the different factors. An increase of $1 \%$ in the stock of human capital per worker, for instance, would increase output by $\alpha_{h} \%$, holding constant the stocks of the other factors and the level of technical efficiency.

For estimation purposes it is generally convenient to work with (1) in logarithms or in growth rates. Using lower case letters to denote logarithms, and the combination of lower case letters and the symbol " $\Delta$ " to denote growth rates, this yields the following two specifications:

(2) $y_{i t}=a_{i t}+\alpha_{k} k_{i t}+\alpha_{h} h_{i t}+\alpha_{l} l_{i t}+\varepsilon_{i t}$

(3) $\Delta y_{i t}=\Delta a_{i t}+\alpha_{k} \Delta k_{i t}+\alpha_{h} \Delta h_{i t}+\alpha_{l} \Delta l_{i t}+\Delta \varepsilon_{i t}$

where $\varepsilon_{i t}$ and $\Delta \varepsilon_{i t}$ are stochastic disturbances.

One difficulty that arises at this point is that both equations (2) and (3) contain terms that are not directly observable (in particular the level of TFP, $a_{i t}$, or its growth rate, $\Delta a_{i t}$ ). To proceed with the estimation, it is necessary to make further assumptions about the behaviour of these terms. Different assumptions will generate different econometric specifications. The simplest possibility is to assume that the rate of technical progress is constant over time and across countries, i.e. that $\Delta a_{i t}=g$ for all $i$ and $t$. In this case, $g$ can be estimated as the regression constant in equation (3) and $a_{i t}$ is replaced in equation (2) by $a_{i o}+$ $g t$, where $a_{i o}$ and $g$ give rise to country-specific constants and a common trend respectively.

An alternative and more sophisticated approach is to specify $\Delta a_{i t}$ in equation (3) as a function of other variables. A relatively general specification of this technical progress function (that nests those used in the studies reviewed in the Appendix to this report and allows for rate effects from human capital) would be given by

(4) $\Delta a_{i t}=\gamma_{i o}+\gamma_{b} b_{i t}+\gamma_{h} H_{i t}+\gamma_{b h} H_{i t} b_{i t}+\gamma_{r} R D_{i t}$

where $H$ is the average stock of human capital, $R D$ a measure of R\&D expenditure and $b_{i t}$ is some proxy for the technological gap between country $i$ and the world best practice frontier.

When data on factor stocks or their growth rates are not available (or are not considered reliable), observed investment rates can be used to construct approximations to the variables that enter equations (2) and (3). These approximations are typically obtained by using a generalized Solow model in the manner suggested by Mankiw, Romer and Weil (1992). In such a model, long-term equilibrium values of factor ratios are simple functions of investment rates, and the behaviour of these ratios away from such an equilibrium can be approximated as a function of investment rates and initial income per worker. If we are willing to assume that most countries are reasonably close to their long-run equilibria, equation (2) can be replaced by an equation relating output per worker to investment rates in physical and human capital. Otherwise, the equation will also include initial output per worker as an additional regressor in order to pick up transitional dynamics along the adjustment to the long-run equilibrium. Two rather standard specifications of the resulting steady state and convergence equations (which do not allow for rate effects) would be

(5) $q_{i t}=a_{i o}+g t+\frac{\alpha_{k}}{1-\alpha_{k}-\alpha_{h}} \ln \frac{s_{k i t}}{\delta+g+n_{i t}}+\frac{\alpha_{h}}{1-\alpha_{k}-\alpha_{h}} \ln \frac{s_{h i t}}{\delta+g+n_{i t}}$

and 


\section{Box 2 (continued)}

$$
\text { (6) } \Delta q_{i t}=g+\beta\left(\frac{\alpha_{k}}{1-\alpha_{k}-\alpha_{h}} \ln \frac{s_{k i t}}{\delta+g+n_{i t}}+\frac{\alpha_{h}}{1-\alpha_{k}-\alpha_{h}} \ln \frac{s_{h i t}}{\delta+g+n_{i t}}\right)+\beta\left(a_{i o}+g t\right)-\beta q_{i t}
$$

where $s_{k}$ and $s_{h}$ stand for investment in physical and human capital, measured as a fraction of GDP, $n$ for the rate of growth of employment or the labour force and $\delta$ for the rate of depreciation (which is assumed to be the same for both types of capital). The parameter $\beta$ measures the speed of convergence towards the long-run equilibrium and can be shown to be a function of the degree of returns to scale in both types of capital considered jointly and of the length of the period over which we are taking observations.

So far, we have implicitly assumed that the stock of human capital per worker, $H$, is directly observable. In practice, however, what we observe is typically average years of schooling, $Y S$, and the estimation of the empirical model requires some assumption about the form of the function relating these two variables, $H=g(Y S)$. Substituting this function into (1), we obtain a reduced-form production function relating $Y$ to $Y S$. To avoid any confusion, we will refer to the elasticity of this reduced-form production function with respect to years of schooling as $\alpha_{Y S}$ (notice that this parameter will generally be different from $\alpha_{h}$ ). Similarly, when $Y S$ replaces $H$ in the technical progress function (4), we will use the notation $\gamma_{Y S}$ for the rate effects parameter that measures the contribution of an additional year of schooling to the rate of TFP growth.

A fairly common assumption in the literature about the nature of $g()$ is that $H=Y S$. In this case, all the equations shown above remain valid, with $H$ replaced by $Y S$ and $\alpha_{h}$ replaced by $\alpha_{Y S}$. A second possibility is to assume that

(7) $H=\exp (\theta Y S)$.

This is often called a Mincerian specification because it is consistent with the functional form commonly used in the microeconometric wage equations pioneered by Mincer (1974). (See Box 1 above). In this case, the exponential in (7) undoes the logarithm in the Cobb-Douglas and the equations above have to be modified accordingly. In particular, logs of $H$ must be replaced by levels of $Y S$ and growth rates of $H$ by average changes in $Y S$. Notice that if we embed (7) into the Cobb-Douglas function given in (2), the coefficient of $Y S$ in the resulting equation, $\rho=\alpha_{h} \theta$, will measure the percentage increase in output that follows from an increase of one year in average school attainment. We will refer to $\rho$ as the aggregate or macroeconomic Mincerian return to schooling. As will become clear later, this variable must be distinguished from the "proper" rate of return to schooling, which will be defined and calculated in section 5.c.

In what follows we will be particularly interested in the values of three technical parameters that can be recovered from structural specifications. The first two are alternative measures of the intensity of level effects: the elasticity of aggregate output with respect to average educational attainment $\left(\alpha_{Y S}\right)$ and what we will call the macroeconomic or aggregate Mincerian return to schooling $(\rho)$. The first of these parameters measures the percentage increase in output that would result from a $1 \%$ increase in average schooling, and the second one the percentage increase in output that would follow from an increase of one year in average attainment. We can go from $\alpha_{Y S}$ to $\rho$ by dividing the first coefficient by average attainment in years and vice versa. The third parameter of interest $\left(\gamma_{Y S}\right)$ measures the intensity of rate effects, i.e. the contribution of one additional year of schooling to the growth rate of total factor productivity. 


\section{iii. Econometric issues}

As we have already noted, measurement error is always an issue in the literature we are reviewing because the years of schooling variable used in most empirical applications is surely a rather imperfect measure of human capital. But even abstracting from this, poor data quality is likely to be an important problem because most existing data sets on cross-country educational attainment seem to contain a considerable amount of noise arising from various inconsistencies in the primary data used to construct them. ${ }^{11}$ Such noise can generally be expected to introduce a downward bias in the estimated human capital coefficients (i.e. a tendency to underestimate their values) because it generates spurious variability in the measured stock of human capital that will not be matched by changes in productivity.

Krueger and Lindhal (2001) discuss some techniques that can be used to construct approximate measures of the quality of different schooling data sets and to correct for measurement error. The information content of a noisy indicator of human capital $(H)$ can be measured by its reliability ratio, defined as the ratio of signal to signal plus measurement noise in the data. Estimates of this ratio can be obtained when several measures of schooling are available, and the results can be used to estimate the size of the biases generated by errors in measurement. It turns out, in particular, that the expected value of the coefficient obtained by standard methods (ordinary least squares) when $H$ is measured with error will be the product of the true value of the parameter and an "attenuation" coefficient that increases with the reliability ratio of the $H$ series used in the estimation. ${ }^{12}$

Using these techniques, we estimate (see section 2.a of the Appendix) that the average reliability ratio of the available cross-country schooling data sets ranges, for a sample of industrial countries, between $10 \%$ and $60 \%$ depending on how the data are measured (i.e. in levels, logarithms or growth rates). This implies that the coefficients estimated in most empirical studies, which do not correct for this problem, are likely to suffer from very significant downward biases and will underestimate the true impact of schooling on growth. The bias will tend to be smaller for estimates obtained using the data in levels or logs, but is likely to be extremely large in specifications that use growth rates of schooling calculated over relatively short periods. ${ }^{13}$

A second standard concern when we are trying to estimate the impact of education on productivity is that reverse causation from income to schooling may generate an upward bias in the estimated coefficient of human capital in the production function. The nature of the problem is discussed in greater detail in Box 3, but it essentially arises because the feedback

\footnotetext{
11 See section 2 of the Appendix for a discussion of the data sets most commonly used in empirical growth analyses.

12 When $H$ is the only regressor, this coefficient is the reliability ratio itself. Otherwise, the error is larger and increases with the $\mathrm{R}^{2}$ of a regression of $H$ on the rest of the explanatory variables in the productivity equation.

13 The average reliability ratio is only 0.278 for the data in quinquennial growth rates, and 0.098 for level differences taken at the same frequency.
} 


\section{Box 3: Reverse causation}

Technically, the source of the reverse causation bias is that the feedback effects of income on education can generate a correlation between schooling and the disturbance of the production function, thereby violating the conditions that are necessary for the consistency of least squares estimators. To illustrate the nature of the problem, suppose that we are trying to estimate a per capita production function in logs

(1) $q_{i t}=a_{i}+g t+\alpha_{k}\left(k_{i t}-l_{i t}\right)+\alpha_{h} h_{i t}+\varepsilon_{i t}$

where $q$ is log output per worker and the rest of the notation is as in Box 2, and that the demand for education is an increasing function of $q$ given by

(2) $h_{i t}=X_{i t} \beta+\eta q_{i t}+v_{i t}$

where $X$ is a vector of other relevant variables and $\varepsilon_{i t}$ and $v_{i t}$ are disturbance terms. In this setup, a positive shock to income in the first equation (a positive value of $\left.\varepsilon_{i t}\right)$ will increase $\left(q_{i t}\right.$ and hence) $h_{i t}$ through the second equation. As a result, the regressor $h_{i t}$ will be positively correlated with the disturbance of the production function and its coefficient will be biased upward.

In practice, things are not necessarily quite as bad as the previous discussion may suggest because average schooling is a stock variable that evolves slowly over time and the level of income should only affect it with a lag through changes in enrollment rates. Thus, we should probably replace equation (2) by something like the following system

(3) $e_{i t}=X_{i t} \beta+\eta q_{i t}+\varphi E_{t} g_{i t+k}+v_{i t}$

(4) $h_{i t}=g\left(e_{i t-1}, \ldots, e_{i t-\kappa}, Z\right)$

where $e_{i t}$ stands for the enrollment rate and the unspecified function $g()$ describes the determination of $h_{i t}$ as a function of past enrollments. Notice that we are making the enrollment rate a function of the expected future rate of technical progress $\left(E_{t} g_{i t+k}\right)$ because, as Bils and Klenow (2000) show, increases in this variable increase the return to schooling and therefore its demand. Notice that with this specification, the problem disappears. Now, a positive shock to income in (1) will increase the enrollment ratio through (3), but this will not feed back into $h$ until some time in the future, implying that $h_{i t}$ can still be uncorrelated with the contemporaneous disturbance in equation (1).

It would be too hasty, however, to dismiss the problem in this way, for it may very well arise in many of the specifications used in the literature, even when direct measures of educational stocks are used in the estimation rather than enrollment rates. For instance, the omission of fixed effects in the production function in levels is likely to cause trouble even in the model described by equations (3) and (4). In this case, the composite error term in (1) would be of the form $\left(a_{i}+\varepsilon_{i t}\right)$ and its time invariant component (the fixed effect) would indeed affect $h_{i t}$ because it will have influenced enrollment in all previous periods. Hence, $h_{i t}$ is very likely to be correlated with $\left(a_{i}+\varepsilon_{i t}\right)$, which will again bias its coefficient.

Reverse causation can also be a problem when the production function is estimated in differences (as is often done, partly to remove the fixed effects bias). We now have

(5) $\Delta q_{i t}=g_{i}+\alpha_{k} \Delta\left(k_{i t}-l_{i t}\right)+\alpha_{h} \Delta h_{i t}+\Delta \varepsilon_{i t}$

where we are allowing for the possibility that the rate of technical progress, $g$, may differ across countries. If equation (5) is well specified, its disturbance term $\Delta \varepsilon_{i t}$ should only contain true random shocks to the growth rate that cannot be anticipated by agents and should not therefore feed back to $\Delta h_{i t}$ through (3) and (4). But if this is not the case and the error term contains some systematic component of the growth rate that agents can anticipate (e.g. a fixed country effect in rates of technical progress), we may well find that $\Delta h_{i t}$ is again correlated with the (enlarged) disturbance, particularly if the period over which we are computing growth rates is long enough for changes in enrollments to affect the stock of schooling of the labour force. 
effects of income on the demand for education can make it difficult to determine to what extent the observed correlation between income and schooling reflects the fact that rich countries demand more education for consumption purposes as well as the contribution of education to productivity that we want to measure.

Since the upward bias arising from reverse causation will work to offset the downward bias from measurement error and may even be larger, there is always some uncertainty about the net bias that remains in any given estimate of the relevant human capital coefficients. While we are not aware of any simple way of estimating the size of the reverse causation bias, the discussion in Box 3 suggests that it may not be very large, particularly in models that control for TFP differences across countries and/or for the determinants of the rate of technological progress and that make use of variables measured in levels or in growth rates calculated over relatively short periods. The main reason for this cautious optimism is that average schooling is a stock variable that evolves slowly over time and should be affected by the level of income only with a considerable lag following changes in enrollment rates (which should indeed be sensitive to income levels). Hence, while reverse causation is likely to be a serious problem when we consider average growth rates over long periods, changes in income over shorter periods should not have time to feed through to schooling stocks. A careful specification of other aspects of the model is also important because the reverse causation problem arises when the residual of the productivity or growth equation is not a "clean" random disturbance but contains systematic components of income or the growth rate that will enter the enrollment equation describing the demand for education because they can be anticipated by individuals. If such contamination can be avoided by controlling for all or most of the relevant factors, the model should yield more accurate estimates of the effects of schooling on productivity.

The preceding discussion suggests that the choice of specification involves a complex tradeoff between different econometric problems, for some of the things that may be done to reduce the reverse causation bias are likely to increase measurement error and vice versa. An additional consideration has to do with the ability of different specifications to capture indirect productivity effects from human capital that involve uncertain and possibly long delays. Specifications that make use of growth rates computed over relatively short periods are unlikely to pick up what we have called rate effects unless these start to work almost immediately, which seems rather implausible. In order to estimate these indirect effects, it may be preferable to work with average growth rates over longer periods or with the data in levels, but it is difficult to be sure that the higher human capital coefficients typically generated by these specifications ${ }^{14}$ are not the result of reverse causation bias.

14 See for instance Topel (1999) and Krueger and Lindhal (2001). 


\section{iv. A brief review of the empirical evidence}

Section 3 of the Appendix to this report contains a detailed survey of the macroeconomic literature on growth and human capital. The picture that emerges from this review of the empirical evidence is somewhat mixed but ultimately encouraging. As we have seen, academic economists have traditionally been inclined to consider educational expenditure a key component of national investment with a substantial payoff in terms of output growth, and have often assigned to the accumulation of human capital a central role in formal models, particularly in the recent literature on endogenous growth. This optimism seemed to be confirmed by a first round of cross-country empirical studies of the determinants of growth, where a variety of educational indicators were consistently found to have the expected positive effect. ${ }^{15}$ A second round of such studies, however, produced rather disappointing results using more sophisticated econometric techniques and even led some researchers to explicitly question the link between education and growth. ${ }^{16}$ In recent years, the evidence seems to be accumulating that such negative results were largely due to poor data and various econometric problems. ${ }^{17}$ Recent studies that make use of improved data sets or allow for measurement error strongly suggest that investment in education does have a substantial impact on productivity growth. 18

Our review of the empirical literature shows that it has proved surprisingly difficult to separate level from rate effects, with different studies reaching opposite conclusions about their relative significance. This may be partly an estimation problem, as the high correlation between schooling levels and growth rates and of these variables with other regressors can make it difficult to untangle their separate effects in a growth regression. ${ }^{19}$ But there are also plausible theoretical specifications in which the two effects may be difficult to identify separately. In particular the distinction between them tends to become blurred once we allow for technological diffusion. In this context, an increase in human capital does make for faster technological change, but this effect gradually exhausts itself as the country comes closer to the world technological frontier and TFP growth stabilizes. As a result, the rate effect becomes a level effect over the medium or long run and, if convergence to the "technological equilibrium" is sufficiently fast, the two effects cannot be separated.

15 See among others Landau (1983), Baumol et al (1989), Barro (1991) and Mankiw, Romer and Weil (1992).

16 Studies that report largely negative findings include Kyriacou (1991), Benhabib and Spiegel (1994), Pritchett (1999, whose first version is from 1995), Islam (1995) and Caselli et al (1996).

17 One of these problems is that the fixed effects specifications used in most of these studies waste all the information contained in the cross-sectional variation of the data. See Section 3 of the Appendix.

18 See for instance de la Fuente and Doménech (2000), Krueger and Lindhal (2001), Cohen and Soto (2001) and Bassanini and Scarpetta (2001).

19 For instance, the correlation between the log and the growth rate of years of schooling is -0.6 in de la Fuente and Doménech's (2001) data set. Using Spanish regional data, de la Fuente (2002b) finds evidence of both level and rate effects in a specification in differences that allows for technological diffusion; the rate effects, however, lose their significance when regional fixed effects are introduced. The author attributes this finding to the high correlation (0.92) between the human capital variable in levels used in this specification and a set of regional dummies. 
As the previous discussion suggests, there remains considerable uncertainty about the size of the relevant macroeconomic human capital coefficients and about the relative importance of level and rate effects. The range of existing estimates is extremely large even when we restrict ourselves to recent studies that make use of the latest available data sets and find evidence of positive growth effects. In Section 5a we will draw on our discussion of the relevant econometric and specification issues and on the detailed literature review contained in the Appendix to try to identify a plausible range of parameter values. What we consider to be the most plausible estimates in the literature suggest that, holding other things equal, an additional year of average school attainment increases the level of aggregate productivity by around $5 \%$ on impact and by a further $5 \%$ in the long run. This second effect reflects the contribution of human capital to technological progress, i.e. to the development and adoption of new technologies and to the continued improvement of existing production processes.

So far we have concentrated on studies that have tried to measure the contribution of increases in the quantity of schooling to productivity growth. Some interesting recent research, however, provides strong evidence that the quality of schooling may be just as important for growth as its quantity, if not more. These studies include mean national scores in standardized achievement tests as explanatory variables in standard growth equations and find large and significant productivity effects. Some of these studies have also analyzed the relationship between student achievement and school expenditure with mixed results. Measures of school resources such as pupil to teacher ratios and average teacher salaries are found to have a significant positive effect on performance in some studies but not in others. ${ }^{20}$ Another important recent finding is that most countries with high average performance of students approaching the end of compulsory schooling are also very successful in raising the performance of students from the most disadvantaged backgrounds (OECD (2001c)). Hence, there is scope for education policies that both raise the average quality of human capital and improve social cohesion.

\section{v. Externalities at the city and regional level}

As we mentioned earlier, comparisons between micro and macroeconomic estimates of the Mincerian returns to schooling may provide a way to assess whether there are externalities associated with the accumulation of human capital. One problem with such comparisons, in addition to those noted above, is that both types of studies generally use quite different data sources. A series of recent studies sidesteps this problem by using the same data source to estimate the returns to schooling within a given country both at the individual level and at the level of cities or regions. (See for instance Acemoglu and Angrist (2000) and Rudd (2000) at the regional level, and Rauch (1993), Ciccone and Peri (2000) and Moretti (2000) at the city level).

20 See Lee and Lee (1995), Barro (2000), Hanushek and Kimko (2000) and Lee and Barro (2001). 
These studies estimate human capital externalities in two steps. The first step consists of estimating the wage-differential between identical individuals working in different cities or regions. This is done using standard Mincerian wage regressions. The second step relates estimated wage differentials between identical individuals in different cities or regions to differences in the average level of human capital between cities or regions. If wagedifferentials can partly be explained by differences in the average level of human capital, then these studies conclude that there are human capital externalities. Because of the lack of appropriate data, none of these studies is done at the country-level.

The findings in this literature range from no human capital externalities to moderate and large externalities. For example, Rauch (1993) finds that a one-year increase in average years of schooling at the city-level is associated with an external effect on city productivity of 3 percent. This finding may however be driven by high-productivity cities attracting high skilled workers, and not by human capital externalities. In fact, Acemoglu and Angrist (2000), Ciccone and Peri (2000) and Rudd (2000) do not find any externalities when they take this possibility into account. Moretti (2000), however, argues that there are large externalities to the share of college-educated workers in US cities. Still, the weight of the evidence suggests that human capital externalities are unlikely to explain a significant part of regional productivity differences.

As all of these studies are done at the city or regional level, they are likely to miss externalities that operate at the country level. For example, suppose that there are human capital externalities at the country level because a greater supply of high human capital workers increases the demand for new technologies and hence the incentives to invest in R\&D. These externalities will not be picked up at the level of cities or regions because new technologies are developed for larger markets. Human capital externalities at the country level must therefore be assessed by comparing estimates of the effect of human capital on individual wages with estimates of its effect on country level productivity.

\section{Social capital and growth}

Social capital as a determinant of economic growth has received much attention in the last decade. It is important to understand at the outset, however, that social capital research is still at its beginnings and that it should be seen as a collection of suggestive arguments and pieces of empirical evidence, rather than as a set of conclusions that can be of direct use in the formulation of economic policy.

The term social capital was rendered popular by the contributions of Coleman $(1988,1990)$ and Putnam $(1993,1995)$ and by now the World Bank (2002) has a website with an entire electronic library on the subject. There are many subtle aspects to defining social capital. For our purpose it is sufficient to see social capital as the norms and social relations embedded in the social structure of a group of people that enables the group or individuals participating in 
it to achieve desired goals. This definition misses what is sometimes called individual social capital, which are the (social) skills that enable an individual to reap market and nonmarket returns from interaction with others. These skills might best be seen as a part of the individual's human capital.

Knack and Keefer (1997) examine various possible empirical proxies for social capital and assess their impact on economic growth at the country level. They discuss two main relationships: between trust and civic norms on the one hand and economic growth on the other, and between associational activity and growth. Trust at the country level is basically measured as the percentage of people responding affirmatively to the following World Value Survey question: 'Generally speaking, would you say that most people can be trusted, or that you can't be too careful in dealing with people?' To capture the strength of norms of civic cooperation, they construct a variable based on answers to various questions about how individuals evaluate anti-civic behavior. Their main finding is that trust and civic cooperation are associated with stronger economic performance, but that associational activity is unrelated to economic growth. This result is quite robust in their sample but it is still unclear whether it also holds in OECD countries (e.g. Helliwell (1996), Zak and Knack (2001)). Temple and Johnson (1998) show that indexes of 'social capability' for the early 1960s, adapted from the work of Adelman and Morris (1967), are good predictors of long run growth for a wide set of developing countries. La Porta et al. (1999) find that social capital improves government performance, including the quality of the bureaucracy and the judicial system. In a study on the development of secondary education in the United States, Goldin and Katz (1999) argue that social capital affects and is affected by human capital accumulation. Guiso, Sapienza and Zingales (2000) use data on Italian regions to show that social capital enhances financial development and access to credit. ${ }^{21}$

What determines social capital (or how is it accumulated)? A full answer to this question is not available, but there are some suggestions. For example, DiPasquale and Glaeser (1999) argue that geographical mobility reduces individual incentives to participate in social capital accumulation, and Alesina and La Ferrara (2000a) find that participation in associational activities like religious groups, sport groups, hobby clubs, etc. is higher when income inequality and racial segmentation are lower. Alesina, Baqir and Easterly (1999) document that more ethnically diverse jurisdictions in the United States devote lower shares of spending to core public goods like education and roads, which is consistent with the idea that ethnic diversity translates into less social capital. There are also some studies on the determinants of trust. Knack and Keefer (1997) find that trust and norms of civic cooperation are stronger in countries with formal institutions that effectively protect property and

21 Besides Putnam's seminal contribution (Putnam 1993a), these are the only two empirical studies on the role of social capital at the regional level that we are aware of. The scarcity of work in this area is due to the fact that there is very little data on institutional quality at the regional level. 
contractual rights, and in countries that are less polarized along lines of class or ethnicity. Helliwell and Putnam (1999) document that higher average education increases trust. Alesina and La Ferrara (2000b) sketch five broad factors influencing how much people trust others: 1) individual culture, traditions and religion; 2) how long an individual has lived in a community with a stable composition; 3) recent personal history of misfortune; 4) the perception of being part of a discriminated group; 5) several characteristics of the composition of one's community, including its racial and income heterogeneity. Glaeser et al. (2000) combine survey and experimental data to separately identify the determinants of trust and of trustworthiness. Two of their findings are that a smaller social distance among individuals, for instance due to joint group membership or the same 'race' or nationality, increases both trust and trustworthiness.

Combining the positive effect of social capital on institutional quality and economic growth with the determinants of social capital suggests that human capital policies that reduce ex-ante inequality as well as the social distance between individuals, i.e. that increase social cohesion, are likely to improve economic performance.

\section{Some tentative conclusions}

The literature surveyed in section 3 and in the Appendix to this report provides a broad range of estimates of the coefficients that measure the contribution of human capital to individual earnings and to aggregate productivity. In this section we attempt to narrow this range by identifying an interval of plausible values for the relevant micro and macroeconomic parameters. These figures are then used to discuss the contribution of human capital to growth and to cross-country income disparities in a sample of industrial countries, and to construct estimates of the private and social rates of return to schooling from which some tentative policy conclusions are drawn.

\section{a. A plausible range of parameter estimates}

On the whole, the range of variation of existing estimates of the Mincerian returns to schooling is considerably smaller at the microeconomic than at the macroeconomic level. While results vary significantly across countries and periods for reasons that have already been discussed, there is less uncertainty in the microeconomic literature about the extent to which estimates for a given sample may be biased in an upward or a downward direction by different econometric problems. There is widespread agreement, for instance, that the measurement error and ability biases roughly offset each other, and that reverse causation is unlikely to be a major problem because higher wages are more likely to increase the demand for education of the children of currently active workers than that of the workers themselves.

A recent study by Harmon, Walker and Westergaard-Nielsen (HW\&W, 2001) provides an estimate of the individual Mincerian returns to schooling parameter $(\theta)$ in fifteen European 
countries (mostly EU members) that is based on a meta analysis of a large number of wage equation estimates undertaken or collected as part of a large research project on the returns to education in Europe. These authors report that the average value of $\theta$ in Europe is $6.5 \% 22$ and that country means range from around $4.5 \%$ to $10 \%$, with the Scandinavian countries and Italy at the lower end of the distribution and the UK and Ireland at the top.

As we have already noted, wage equation coefficients have to be treated with some precaution when interpreted as estimates of the technical parameter that measures the contribution of schooling to productivity because it is likely that payscales will reflect labour market institutions and social norms as well as relative productivities. Making some allowance for the distortions created by wage-setting practices, it may be expected that the true value of the Mincerian parameter will lie somewhere between HW\&W's central estimate of $6.5 \%$ and their average estimate of $9 \%$ for the Anglo-Saxon countries that appear to have the most flexible labour markets in Europe. Table 1 gathers these two benchmark estimates of the individual "raw" returns to schooling $(\theta)$ and the values that result after the adjustment for physical capital that is required to make them comparable to the relevant macroeconomic returns to schooling coefficient $(\rho) .^{23}$

Table 1: Benchmark estimates of the individual Mincerian returns parameter $(\theta)$ and values adjusted for comparison with macroeconomic estimates $(\rho)$

\begin{tabular}{lcc}
\hline & raw & adjusted \\
& $\theta$ & $\rho$ \\
$\min$ (average) & $6.50 \%$ & $4.33 \%$ \\
$\max$ (Anglo-Saxon countries) & $9.00 \%$ & $6.00 \%$ \\
\hline
\end{tabular}

At the macroeconomic level, identifying a plausible range of values for the relevant parameters is a much more difficult task because the available estimates vary from negative to very large positive values. Drawing on our discussion of the literature, we will argue that the elasticity of output with respect to average years of schooling $\left(\alpha_{Y S}\right)$ can be expected to lie between 0.394 and 0.535 and that the rate effects coefficient $\left(\gamma_{Y S}\right)$ should be between $0.0 \%$ and $0.9 \%$. The first set of figures implies that the Mincerian level effects parameter $(\rho)$ can be expected to fall between $3.98 \%$ and $5.41 \%$ for the case of the average EU country in 1990, as shown in Table $2 .{ }^{24}$

22 This is very similar to the average estimate of $6.8 \%$ for the OECD countries reported by Psacharopoulos (1994).

23 We estimate $\rho$ as $\left(1-\alpha_{k}\right) \theta$ with $\alpha_{k}=1 / 3$. See Section 3 for a discussion of the nature of the adjustment.

24 This calculation assumes that the aggregate production function is Cobb-Douglas in years of schooling, i.e. that $H=Y S$. The value of $\rho$ is obtained by dividing the relevant estimate of $\alpha_{Y S}$ by average 1990 school attainment in years in the sample of 14 EU countries (all but Luxembourg) for which de la Fuente and Doménech (2001) provide data. 
Table 2: Benchmark estimates of the macroeconomic level and rate parameters

\begin{tabular}{ccc}
\hline & level effects & rate effects \\
& $\rho$ & $\gamma_{Y S}$ \\
$\min$ & $3.98 \%$ & $0.00 \%$ \\
$\max$ & $5.41 \%$ & $0.90 \%$ \\
\hline
\end{tabular}

A detailed discussion of how these figures are obtained from various estimates in the literature is included in section $3 \mathrm{f}$ of the Appendix. To arrive at this range of values, we disregard the most pessimistic results in the literature as the result of poor data quality. Our lower bound estimate comes from an updated version of de la Fuente and Doménech (2000) that makes use of a recently constructed data set which appears to have a relatively high signal to noise ratio. This paper estimates a production function using growth rates calculated over five-year intervals and contains a fairly complete specification of the technical progress function that allows for technological diffusion and for country fixed effects that should help control for omitted variables such as R\&D investment. As a result of both the high frequency of the observations and the specification used, these estimates are very unlikely to suffer from a significant upward bias arising from reverse causation. It is more likely that they will underestimate the true returns to schooling because of remaining measurement error and because the shortness of the period over which the growth rates are computed can make it difficult to detect productivity effects that may involve considerable lags -- as is likely to be the case with the technology-related rate effects.

A conservative correction for measurement error brings de la Fuente and Doménech's estimate of the value of $\rho$ in the EU to $5.41 \% .{ }^{25}$ Since this figure is well within the range of the (adjusted) microeconometric estimates shown in Table 1, we will use it as an upper bound on the likely value of the level effects. ${ }^{26}$ Hence, coefficients of schooling variables in growth

25 The correction is conservative because it is based on the estimated reliability ratio for this schooling series (0.736) without taking into account the further adjustment that would be required because of the correlation between schooling and other regressors included in the equation. The full correction would lower the attenuation factor to 0.2 and increase five-fold the original estimate of the parameter. On the other hand, it is very likely that this procedure will lead to the overestimation of the true parameter, as measurement error in the other regressors is likely to partially offset the downward bias on schooling.

26 An additional reason for this choice is that, under the assumption that the reduced-form production function is Cobb-Douglas in schooling (i.e. that $H=Y S$ ) the output elasticity that corresponds to this estimate $\left(\alpha_{Y S}=0.535\right)$ implies that the returns to schooling account for $82 \%$ of labour income. Under the same assumption, any significantly higher estimate of $\rho$ would imply a negative coefficient for raw labour in the aggregate production function and a negative share of this factor in labour compensation. The CobbDouglas assumption, however, is crucial for this argument because it implies that $\alpha_{Y S}=\alpha_{h}$ (see Box 2). With a Mincerian specification $(H=\operatorname{Exp}(\theta Y S))$, the share of skill in total labour compensation cannot be inferred from the parameters of the reduced-form production function relating output to schooling. The reason is that, while this share still depends on $\alpha_{h}$, this parameter is now different from $\alpha_{Y S}$ and cannot be identified separately because it enters the reduced-form production function multiplying $\theta$. 
equations that imply higher values of $\rho$ must be picking up something else than the direct productivity or level effects that are likely to translate into higher wages.

There are essentially two possibilities: one is the upward bias from reverse causation, and the other what we have called rate effects, i.e. the indirect contribution of human capital to growth via faster technical progress that constitutes the most plausible source of externalities linked to education. ${ }^{27}$ The pattern of results in the studies that produce large estimates of $\rho$ suggests that both factors are at work. Schooling coefficients are generally larger when they come from steady state level equations (where reverse causation can be a serious problem if we do not control for differences in TFP levels across countries) or from differenced specifications that use growth rates computed over long periods (where again there is greater danger of reverse causation bias as there is time for changes in enrollments to affect schooling stocks). On the other hand, these specifications are also more likely to pick up productivity effects that involve long gestation lags, and there are reasons to expect that not all of the observed increase in the coefficients is due to reverse causation. In particular, some of the relevant studies that estimate steady state equations do include proxies for TFP or other control variables that should at least reduce the endogeneity bias (e.g. Cohen and Soto (2001) and Barro (2000)), and one of them (Bassanini and Scarpetta (2001)) estimates very high schooling coefficients with annual data using an error correction specification that probably permits a better characterization of long-term relationships by allowing short-term deviations from them.

The range of values shown in Table 2 for the rate effects parameter, $\gamma_{Y S}$, is obtained by imposing the assumption that $\alpha_{Y S}=0.535$ and solving for the value of $\gamma_{Y S}$ that is consistent with the schooling coefficients obtained in different studies, when these coefficients are interpreted within the context of a model allowing for technological diffusion (see Box 4 below and Section $3 \mathrm{f}$ of the Appendix). The coefficient estimates we use are taken from the studies cited above and from a paper by Jones (1996) that attempts to estimate directly the rate effects (essentially by assuming that there are no level effects). The values of $\gamma_{Y S}$ obtained in this manner range from $0.24 \%$ in Cohen and Soto (2001) to $0.87 \%$ in Barro (2000).

\section{b. Implications for growth and cross country disparities in the OECD}

How important is human capital as a source of growth and cross-country productivity disparities? In this section we will provide a tentative answer to this question for a sample of 21 industrial countries. In particular, we will calculate the contribution of human capital to i) the observed growth in productivity (measured by output per employed worker) over the period 1960-1990 and ii) the productivity differential with the sample average in 1990,

27 A third possibility is that schooling may act as a proxy for R\&D investment, which is highly skill intensive. While this is not exactly the idea behind the rate effects, a positive coefficient arising through this mechanism would also be consistent with the view that human capital contributes to the creation of useful knowledge. 


\section{Box 4: Measuring the contribution of schooling to growth and cross-country disparities}

The contribution of human capital to growth in country $i\left(c h_{i}\right)$ is calculated using an aggregate production function (which is assumed to be Cobb-Douglas in average years of schooling, YS) and a technical progress function that allows for rate effects from human capital and technological diffusion. Hence, $c h_{i}$ will have two components in the general case. The first one captures level effects and is given by

(1) $c h_{l i}=\alpha_{Y S} \Delta y s_{i}$

where $\alpha_{Y S}$ is the elasticity of output with respect to average schooling and $\Delta y s_{i}$ is the observed growth rate of average years of schooling in country $i$ over the sample period. The second component captures the contribution of rate effects and is calculated using a technical progress function of the form

(2) $\Delta x_{i t}=\gamma_{i o}-\lambda x_{i t}+\gamma_{Y S} Y S_{i t}$

where $x_{i t}$ is the log of country $i$ 's TFP level at time $t$, measured as a fraction of the world technological frontier. For this calculation we assume that in 1960 all countries were in the technological steady states (relative to the world frontier) corresponding to their estimated schooling levels in 1955. These are obtained by projecting backward the value of YS in 1960 using the growth rate of this variable between 1960 and 1965. These initial values are then projected forward until 1990 using equation (3) and the values of $Y S$ observed during the sample period. Finally, the annualized difference between the initial and final values of $x_{i t}$ is used as our estimate of the contribution of rate effects to growth in country $i$.

The share of human capital in growth in country $i$ is then given by the ratio $a_{i}={ } h_{i} / \Delta q_{i}$ where $\Delta q_{i}$ is the observed value of the growth rate of output per worker over the period 196090. To reduce the weight of outliers, rather than computing the simple average of this quantity across countries, we estimate a regression of the form

(3) $c h_{i}=a \Delta q_{i}+e_{i}$

where $e_{i}$ is a disturbance term. The coefficient $a \cong c h_{i} / \Delta q_{i}$ measures the fraction of observed growth that can be attributed to human capital in the case of a typical country in the sample.

To measure the contribution of human capital to productivity differentials in 1990 we proceed in a similar way. We define country $i$ 's relative productivity $\left(\right.$ qrel $\left._{i}\right)$ as the difference between country $i$ 's log output per employed worker in 1990 and the average value of the same variable in the sample and regress human capital's estimated contribution to qrel $_{i}$ on qrel $_{i}$ itself to obtain a coefficient, analogous to $a$ in equation (3), that measures the fraction of the productivity differential that can be attributed to human capital in a typical country in the sample. As before, the contribution of human capital to relative productivity will have two components that reflect level and rate effects respectively. The first component is computed by multiplying $\alpha_{Y S}$ by the country's relative level of schooling (measured in log differences with the (geometric) sample average) and the second is obtained as the difference between the 1990 value of $x_{i}$ estimated above and the sample average of the same variable.

working in both cases with a "typical" OECD economy. This fictional typical economy is constructed by averaging across countries the contributions of human capital to the variables of interest using regression-based weights so as to reduce the impact of outliers (see Box 4). The exercise will be repeated for the range of values of the schooling coefficients identified in the previous section. This will allow us to illustrate the implications of the different parameter estimates available in the literature in terms of magnitudes that are easy to interpret, and may serve as a check on the plausibility of these estimates. All our calculations are made with the data set used in the updated version of de la Fuente and Doménech (2000) and these authors' estimates of the parameters of the production and 
technical progress functions (except in the case of the schooling coefficients, which are allowed to vary over the entire range of values discussed above).

Figure 3: Percentage of growth in output per worker during 1960-90

explained by human capital in a typical OECD country as a function of the rate effects parameter

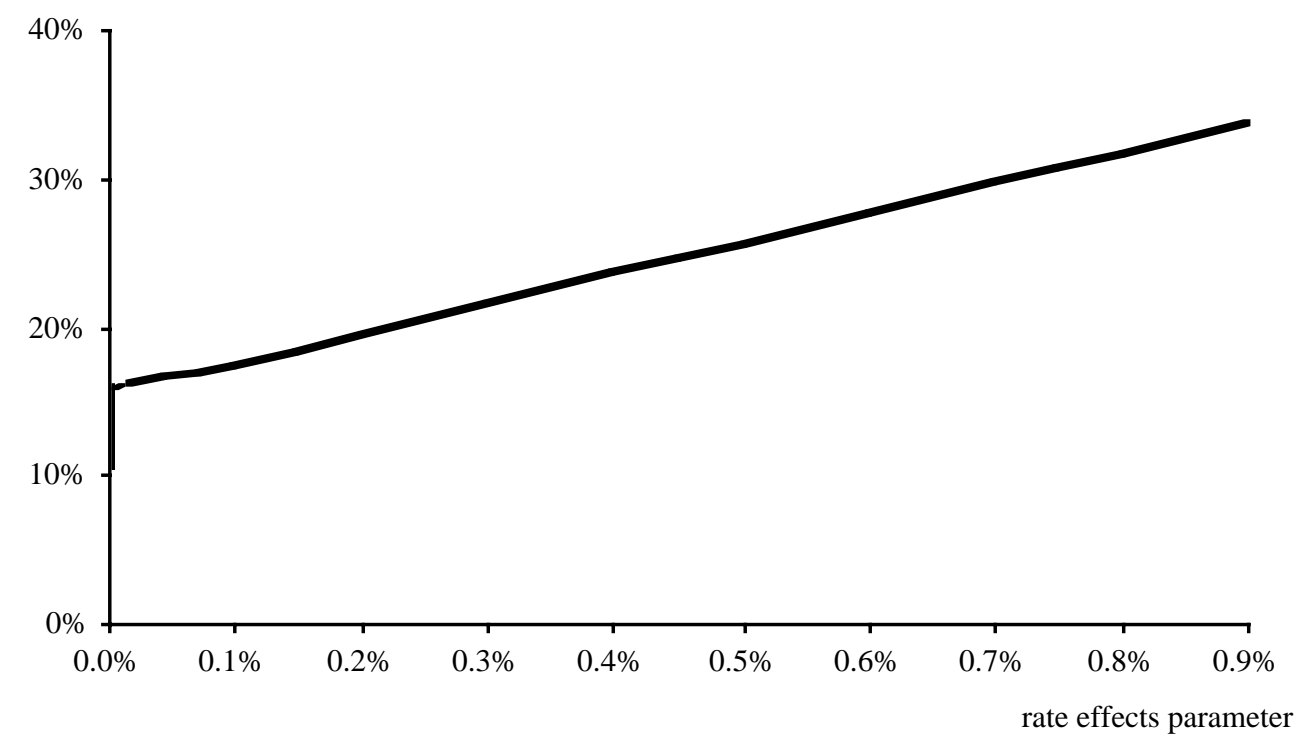

Figure 4: Percentage of disparities in output per worker in 1990 explained by human capital in a typical OECD country as a function of the rate effects parameter

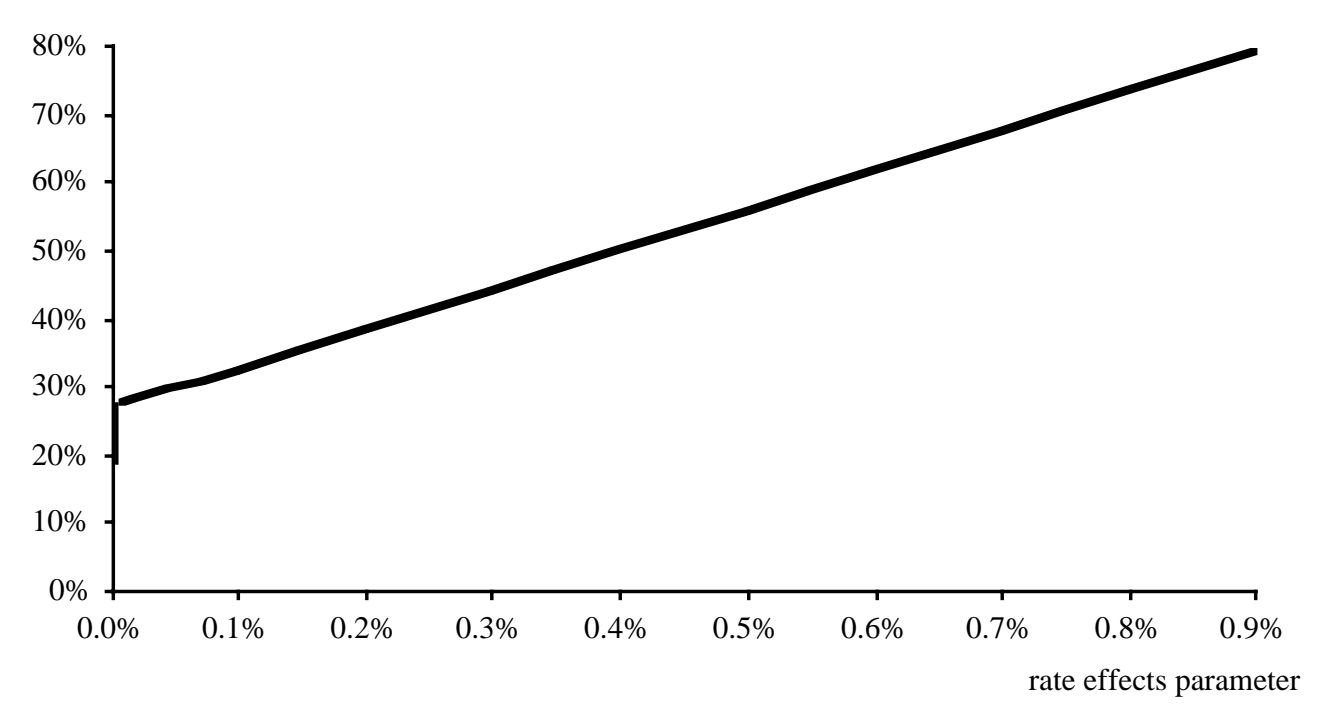

Figures 3 and 4 show the share of human capital in observed growth and in the productivity differential with the sample average ("relative productivity," from now on) in the case of a typical OECD country. Both shares are shown as functions of the assumed value of the rate effects parameter, $\gamma_{Y S}$. The vertical segment of each curve, drawn along the vertical axis, corresponds to the range of values implied by our maximum and minimum 
estimates of the level effects parameter. If we consider only level effects, human capital accounts for between $11.31 \%$ and $15.36 \%$ of productivity growth over $1960-90$ and for between $19.52 \%$ and $26.51 \%$ of the productivity differential with the sample average in 1990. These are respectable figures, and they increase rapidly when the contribution of the rate effects is added, reaching $33.71 \%$ of growth and $79.10 \%$ of relative productivity for $\gamma_{Y S}=0.9 \%$. These results indicate that human capital is relatively more important in accounting for remaining productivity disparities than in explaining past growth. The reason for this is that the stock of physical capital has grown more rapidly than average years of schooling and has converged at a faster pace across countries, thereby reducing the contribution of this factor to observed productivity disparities.

Table 3: Immediate sources of productivity growth and cross country productivity differentials

\begin{tabular}{lcc}
\hline & $1960-90$ & 1990 \\
growth & $\begin{array}{c}\text { relative } \\
\text { levels }\end{array}$ \\
contribution of: & rates & $38.02 \%$ \\
physical capital & $49.39 \%$ & $26.51 \%$ \\
schooling (level effect) & $15.36 \%$ & $64.53 \%$ \\
total $k+$ ys level & $64.75 \%$ & $35.47 \%$ \\
rest = due to TFP & $35.25 \%$ &
\end{tabular}

- Note: Shares of different factors in observed growth and relative productivity in a typical OECD country as defined in Box 4 .

Following Bils and Klenow (2000), the following calculation may be helpful in narrowing down the plausible range of values of the rate effects parameter. Subtracting from observed productivity growth and from relative productivity the contribution of physical capital and (the upper bound on) the level effects from human capital, we obtain the share of total factor productivity (TFP) in these variables which, as shown in Table 3, is around one third in both cases. Figure 5 then plots the contribution of rate effects to growth and to relative productivity as a fraction of the estimated TFP share. A "large" value of either of these ratios will render the underlying rate effects coefficient suspect. For instance, the finding that rate effects are greater than observed total TFP growth would imply that other components of this variable (which would capture among other things the contribution of R\&D investment) must have declined over time, which seems rather implausible. A similar finding in the cross-section dimension would imply that the component of TFP levels not related to human capital would have to be negatively correlated with labour productivity which, again, seems unlikely. Turning to Figure 5, the growth decomposition does not help narrow the range of values of $\gamma_{Y S}$ as even the most optimistic estimates available in the literature imply that human capital accounts for less than half of the observed growth in TFP. On the other hand, the cross-section relative productivity comparison suggests that we should rule out estimates 
of $\gamma_{Y S}$ greater than $0.6 \%$, and that values of this parameter over $0.3-0.4 \%$ are unlikely because they would imply that more than half of the observed cross-country TFP differentials are induced by human capital. ${ }^{28}$

Figure 5: Impact of the rate effects from human capital as a $\%$ of the total contribution of TFP to growth and relative productivity

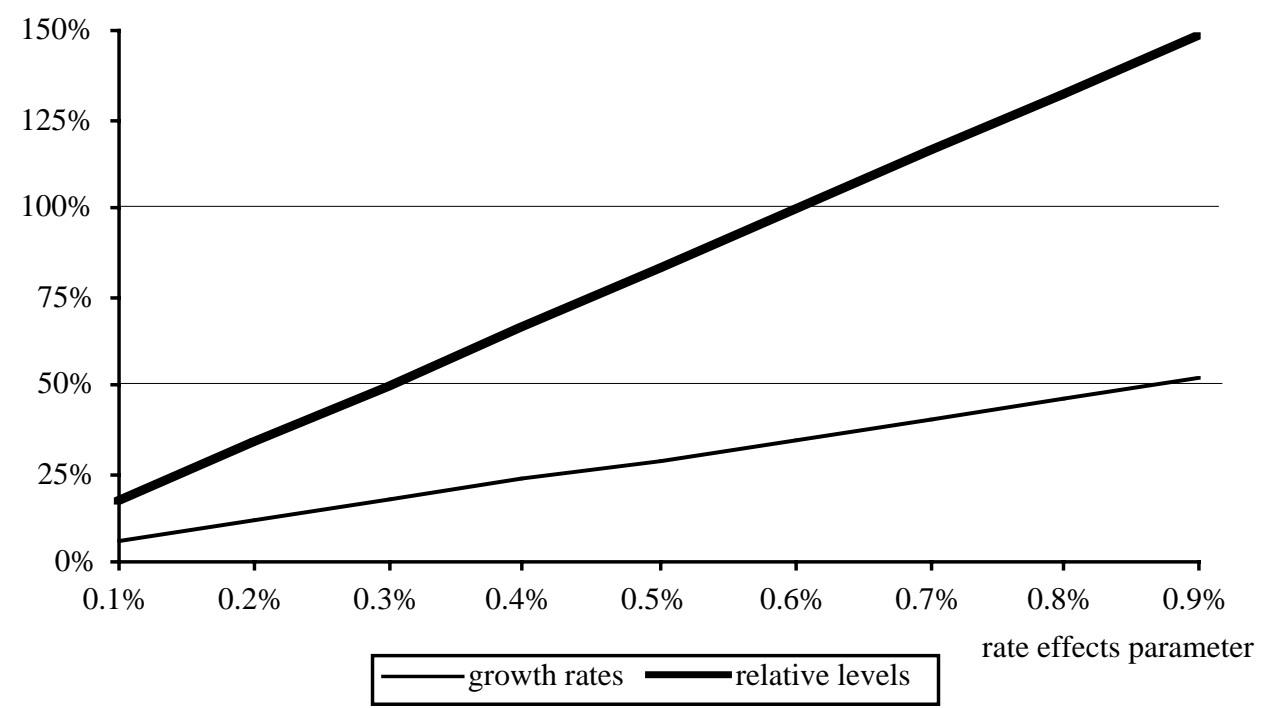

\section{c. Rates of return to schooling and some policy implications}

In this section we will compute the "proper" rates of return to schooling implied by the micro and macroeconomic parameter estimates discussed above. This calculation is necessary in order to turn our estimates of technical parameters into measures of the net private and social economic benefits of schooling that can be compared with each other (by combining level and rate effects into a single indicator) and with the returns on alternative assets. As we have already noted, such comparisons can yield information that will be of interest for policy formulation because they may alert us to under or overinvestment in education, or to the existence of externalities that may call for corrective action.

Box 5 discusses the methodology used for the calculation of these rates of return. We compute the internal rate of return on schooling, defined as the discount rate that makes the

28 It should be noted that not all analysts would agree with this criterion. Wössman (2000), for instance, performs a similar levels accounting exercise with a Mincerian measure of the stock of human capital that corrects for quality differences using an indicator constructed by Hanushek and Kimko on the basis of international test scores (see section 3.e of the Appendix). He finds that practically all differences in output per worker across OECD countries are explained by human capital (leaving a negative share for TFP that roughly offsets the share of physical capital). While Wössman argues that this result should be taken at face value, we think it is too "optimistic" because it leaves virtually no room for other factors that are likely to be important sources of productivity disparities.

It should also be noted that a value of $\alpha_{k}$ somewhat lower than the one used in our computations would still be consistent with national accounts data on factor shares (particularly when capital income is corrected for the earnings of self-employed workers). A lower value of this parameter will reduce the share of physical capital in growth and productivity differentials and raise that of TFP, thus leaving more room for human capital. For plausible values of $\alpha_{k}$, however, this would not greatly affect our conclusions. 
net present value of the increase in earnings generated by a marginal change in schooling equal to the present value of the relevant stream of costs. We distinguish between gross and net rates of return. Gross rates of return are obtained by ignoring the direct costs of schooling (but not its opportunity costs in terms of foregone earnings), while net rates of return take into account the relevant direct costs (either those paid directly by the individual or the sum of the former and government educational expenditures). Our estimates of direct costs are based on recent data on total and government expenditure on secondary and higher education in the average EU country and try to approximate the cost of a marginal increase in enrollments, which would have to come at the upper secondary and university levels since attendance at lower levels is already compulsory in these countries.

\section{Box 5: The rate of return to schooling}

Consider an individual who goes to school the first $S$ years of his adult life and retires at time $T$. If each year of schooling has a direct $\operatorname{cost} c$, the net present value (at time zero) of earnings over his working life is given by

$$
\text { (1) } V(S)=\int_{S}^{T} A(t) f(S) e^{-r t} d t-\int_{0}^{S} c(t) e^{-r t} d t
$$

where labour income at time $t$ is given by the product of a technical efficiency index $A(t)$ and a function $f(S)$ that increases with schooling. The net marginal value of schooling will be given by the derivative of this function, $V^{\prime}(S)$. By setting this derivative equal to zero and solving the resulting equation for the value of the discount rate, $r$, we will obtain an estimate of the proper rate of return to schooling.

We will use this approach to compute the individual and social rates of return to schooling distinguishing between gross and net rates of return as defined in the text. When we apply this procedure to an individual to compute the private rate of return, we will consider technical progress to be exogenous (i.e. assume that the evolution of $A(t)$ is not affected by the individual's schooling choice). To compute the social rate of return, we will apply the same procedure to a hypothetical average individual. This must be regarded as an approximation because the computation implicitly assumes that a one-year increase in average attainment will be obtained by immediately sending the entire labour force to school for a year (rather than by gradually raising the attainment of younger cohorts). When computing social rates of return, we will allow for rate effects (i.e. assume that the average value of $S$ in the aggregate can have an effect on technical progress). In this case, an additional term must also be added to $V(S)$ in equation (1) above to capture the impact of current schooling on TFP beyond the working life of the currently active cohorts. The specific technical progress function underlying our calculations is the same one used in Box 4, i.e.

(2) $\Delta x_{i t}=\gamma_{i o}-\lambda x_{i t}+\gamma_{Y S} S_{i t}$

where $-x_{i t}$ measures the distance to the world technological frontier, which is assumed to shift out over time at a constant rate $g$, and $\lambda$ can be interpreted as the speed of technological diffusion.

Under the assumption that the direct costs of schooling are a given fraction $\mu$ of output per employed worker, the net social rate of return to education will be given by ${ }^{29}$

(3) $r=R+g$

where $g$ is the world rate of technological progress and $R$ solves the following equation

(4) $R=\frac{1-e^{-R U}}{1+\mu}\left(\rho+\frac{\gamma_{Y S}}{R+\lambda}\right)$.

${ }^{29}$ See de la Fuente (2002a) for a derivation of this result. 


\section{Box 5 (continued)}

In this expression, $\rho=f^{\prime}(S) / f(S)$ is the aggregate Mincerian returns to schooling parameter (for the EU), $U=T-S$ the duration in years of the working life of the representative individual and the rest of the terms have been defined above. This formula can be applied with suitable modifications to the other cases of interest. To obtain the gross social rate of return, we set $\mu=0$ in (4); to calculate private returns, we set $\gamma_{Y S}=0$ and replace $\rho$ by the relevant (adjusted or unadjusted) individual Mincerian parameter $(\theta)$.

For the calculations reported in this section, we assume that $g=0.015, \lambda=0.074$, and $U=$ 42. The first estimate is taken from Jones (2002), the second from an updated version of de la Fuente and Doménech (2000) and the third is chosen as a plausible value for industrial countries, where younger cohorts often leave school in their twenties and workers tend to retire before turning 65 .

The values of $\mu$ used in the social and private returns calculation are $12.45 \%$ and $0.93 \%$ respectively. The first figure is derived as a weighted average of total expenditure on secondary and university education (with weights of $2 / 3$ and $1 / 3$ respectively) in the average EU country (excluding Luxembourg) as reported in the 2000 edition of the OECD's Education at a Glance. This source reports expenditure as a fraction of GDP per capita in 1997. We estimate $\mu$ as a fraction of output per worker by multiplying the original figure by the ratio of employment to the total population in 1990, taken from an updated version of Doménech and Boscá (1996). The value of $\mu$ relevant for the private returns calculation is estimated by multiplying the previous figure by the share of educational expenditure financed by the private sector in the same sample of countries, which is taken from the same OECD source. The OECD reports these data separately for tertiary studies and for all other educational levels combined, so we again take a weighted average with a weight of $1 / 3$ for higher education.

Our calculations of private returns are based on Mincerian estimates that capture the average return to one more year of schooling across all educational levels and are therefore not comparable to estimates based on wage premia for specific levels of education. They can also differ from the realized returns over specific periods because wage trends for different educational categories may deviate from the overall rate of technical progress assumed here.

It should be noted that the rates of return we compute do not incorporate the non-market returns to schooling in home production and leisure (see section 3a.xi) and fail to take into account the direct consumption value of education and its impact on labour force participation and employment probabilities. As a result, they will underestimate the true returns to schooling by an amount that may be large but it is extremely difficult to measure with precision.

The formula given in equation (4) of Box 5 shows that the technical parameter we have called the Mincerian returns to schooling is a proper rate of return only under very special assumptions that do not hold in practice. To obtain proper rates of return, the estimated Mincerian coefficients have to be adjusted for the direct costs of education, for the finiteness of individuals' working lives, for technical progress and for rate effects, whenever these are relevant.

Table 4 shows the proper gross and net rates of return implied by the range of parameter values given in Tables 1 and 2 above for the average EU14 country in 1990. At the individual 
level we report rates of return based on both the unadjusted and the adjusted Mincerian parameters. The first set of values measures the private incentives to invest in formal education and the second set can be compared with macro estimates for the purpose of quantifying the importance of externalities. The last block of the table contains estimates of the rate of return on alternative assets. The returns on US stocks and government bonds are taken from Arias and McMahon (2001) and are average values for the period 1975-95. ${ }^{30}$ The rate of return on physical capital is calculated as $r_{k}=M P_{k}-\delta+g$ where $M P_{k}$ is the marginal product of this factor, $\delta$ the rate of depreciation and $g$ the rate of technical progress. ${ }^{31}$ Our estimate of $M P_{k}(=13.1 \%)$ is the average value of the marginal product of capital in 1990 in a sample of $14 \mathrm{EU}$ countries computed using the production function estimated in the updated version of de la Fuente and Doménech (2000) and the data used by these authors, which includes an estimate of the stock of physical capital. We assume a depreciation rate of $5 \%$ and a value of $g$ of $1.5 \%$ (as in the calculations of the rate of return to education). This is in rough agreement with the estimate of $15 \%$ for the US given in McMahon (1991) for the marginal product of (non-residential) capital based on Bureau of Economic Analysis data on capital income and the capital stock.

Table 4: Rates of return to schooling and to some alternative assets

\begin{tabular}{lcc}
\hline & gross & net \\
$\begin{array}{l}\text { unadjusted private returns: } \\
\text { min }(\theta=6.5 \%)\end{array}$ & $5.97 \%$ & $5.90 \%$ \\
max $(\theta=9 \%)$ & $8.77 \%$ & $8.68 \%$ \\
$\begin{array}{l}\text { adjusted private returns: } \\
\text { min }(\rho=4.33 \%)\end{array}$ & $4.71 \%$ & $4.65 \%$ \\
max $(\rho=6.00 \%)$ & $6.87 \%$ & $6.80 \%$ \\
social returns: & & \\
min $\left(\rho=3.98 \%, \gamma_{Y S}=0\right)$ & $4.20 \%$ & $3.53 \%$ \\
interm $\left(\rho=5.41 \%, \gamma_{Y S}=0\right)$ & $6.15 \%$ & $5.36 \%$ \\
max $\left(\rho=5.41 \%, \gamma_{Y S}=0.90 \%\right)$ & $11.85 \%$ & $10.89 \%$ \\
returns to alternative assets: & & \\
large company equity $(U S)$ & & $7.70 \%$ \\
US government bonds & & $2.60 \%$ \\
physical capital & & $9.60 \%$ \\
\end{tabular}

- Note: Unless otherwise indicated, these figures refer to an average EU country around 1990.

A number of pairwise comparisons between these different rates of return can be informative. Figure 6 displays the gross social and (corrected) private rates of return to

\footnotetext{
30 We use data for the US because we have not found comparable data for the EU, but we do not expect that existing differences will be large enough to affect our conclusions.

31 This formula comes out of a calculation analogous to the one described in Box 5, which is much simpler in the case of physical capital because of the absence of delays and rate effects.
} 
schooling, with the former shown as a function of the rate effects parameter, $\gamma_{Y S}$. The figure illustrates the implications of the broad spread of parameter estimates found in the literature for the importance of externalities. At the lower end of the range, our macroeconomic parameter estimates are consistent with their microeconometric counterparts and suggest that the productivity effects of human capital, while sizable, are fully reflected in wages. The upper range of the estimates, however, implies that technology-related externalities are extremely large, and account for up to one half of the social return to education. For the more plausible intermediate estimates of the rate effects parameter ( 0.3 to $0.4 \%$ ), technological externalities add between two and a half and three points to the social return to education.

Figure 6: Gross social and adjusted private returns to schooling as a function of $\gamma_{Y S}$

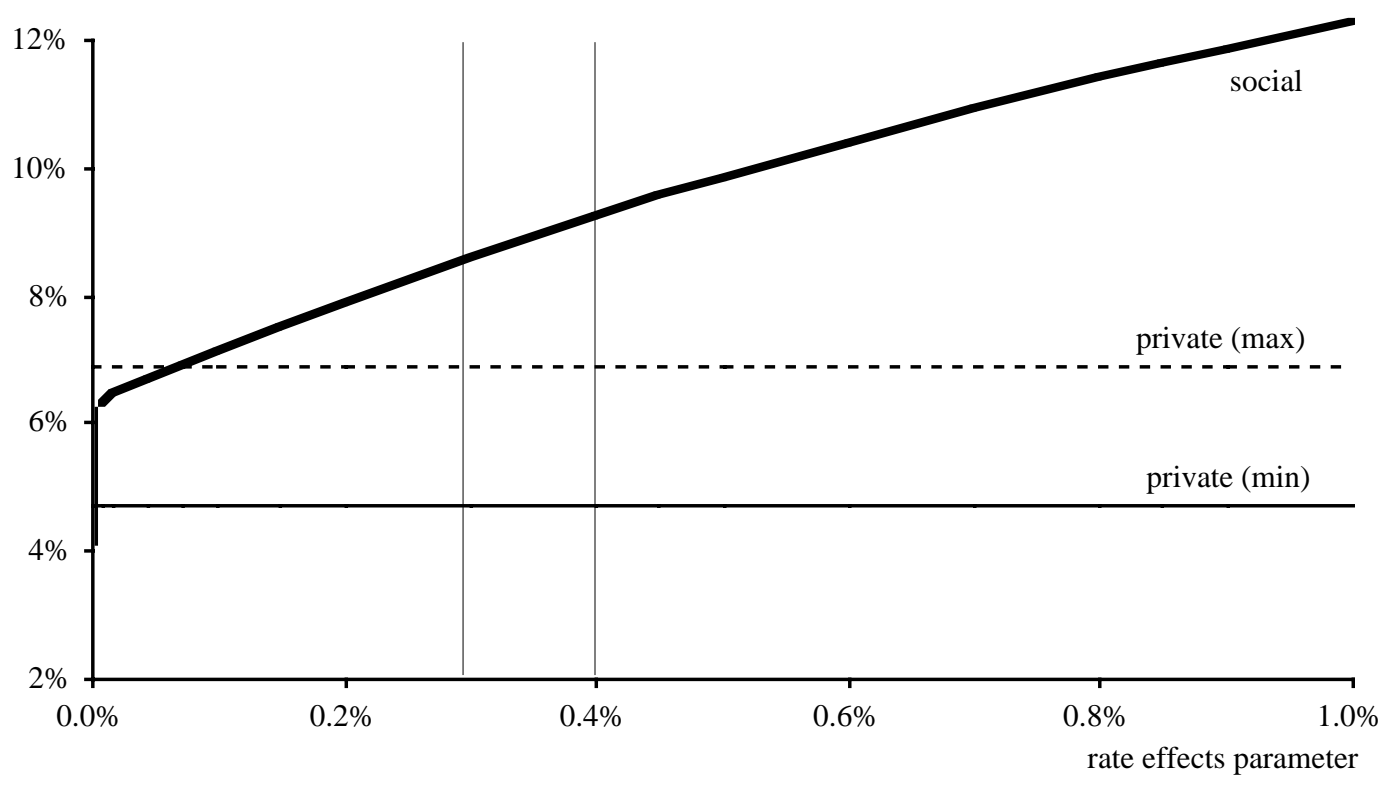

In the absence of public intervention, the existence of externalities of the type the macroeconometric estimates seem to be picking up would generate a tendency for private underinvestment in schooling. Most governments, however, heavily subsidize education and have enacted compulsory schooling laws. Since both types of measures will tend to raise educational investment, thus counteracting the effects of the externalities, the level of schooling we observe may be either too high or too low when compared with the social optimum. A comparison of the returns to schooling with those available from alternative productive assets can potentially give us some information about the optimality of the outcome observed in the average EU country.

In principle, the relevant comparison would be between the net social returns to education and the returns to physical capital. In practice, there is considerable uncertainty about the values of the relevant rates of return. In addition to the existing uncertainty about the size of 
the external effects of education that have been emphasized in this report, there are two considerations. The first one is that, as we have already noted, our estimates are likely to understate the social rate of return to education because they only consider direct productivity effects. The second is that it is not entirely clear how we should measure the return to physical capital. Our production function-based estimate of this magnitude is significantly larger than observed stock returns (which, incidentally, include the returns on all corporate assets, and not only on physical capital). One possible reason for this is that we may be underestimating the relevant rate of depreciation or overestimating the coefficient of physical capital in the production function, $\alpha_{k}$, and a second one that stock returns are net of intermediation costs that may be considerable and should probably not be counted as part of the net return to capital. At any rate, it may be expected that the relevant rate of return on physical capital should fall somewhere between these two magnitudes.

Figure 7: Net social returns to schooling vs. returns to physical capital

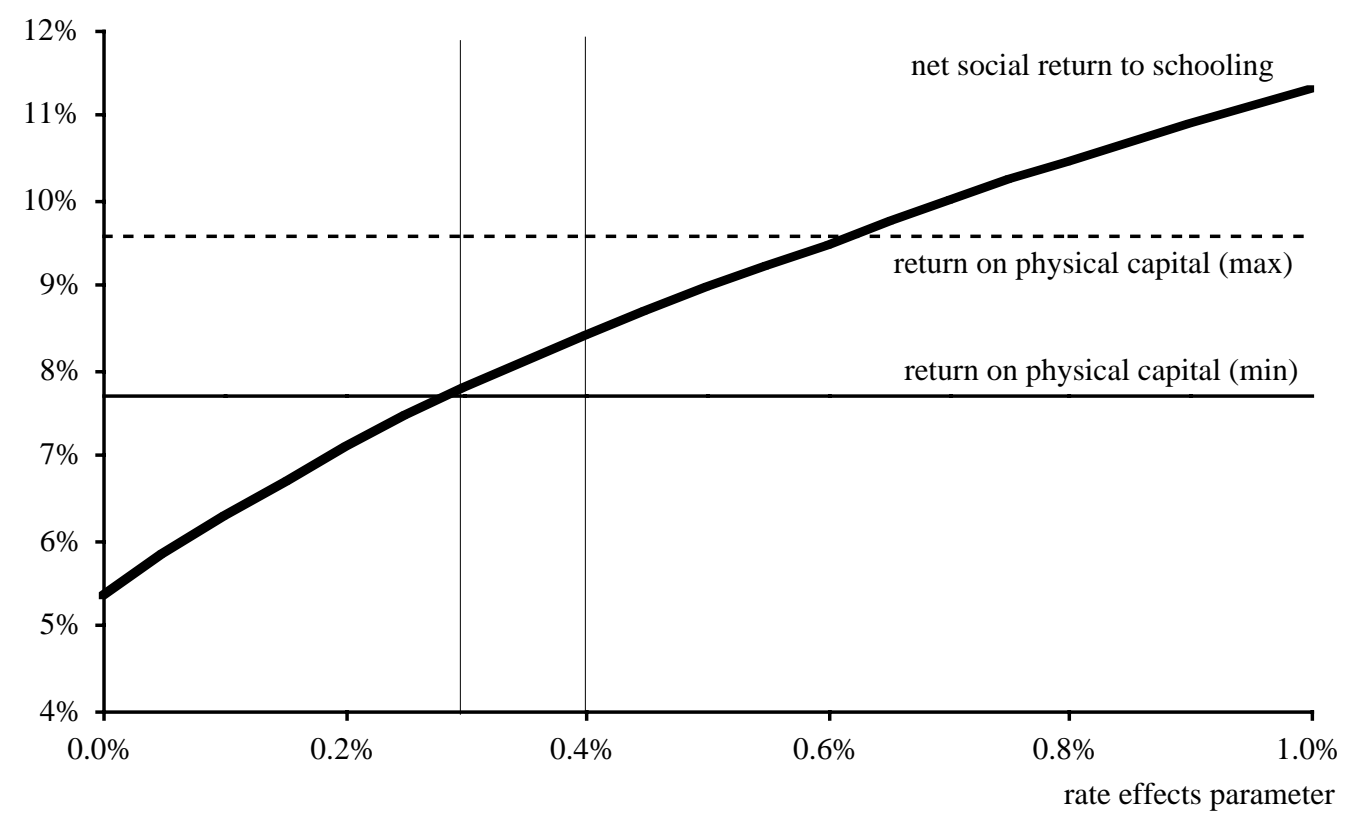

Figure 7 plots the net social returns to schooling as a function of the rate effects parameter $\left(\gamma_{Y S}\right)$ together with the plausible range of rates of return on physical capital. Values of $\gamma_{Y S}$ that fall about half-way within the range of existing estimates suggest that the direct economic returns to schooling are probably in line with those available from investment in physical capital. Since our measure of the social returns to education does not include its nonmarket benefits, or those derived from its contribution to social cohesion, a plausible case can be made for the view that an increase in human capital investment may be justified. This argument, however, relies on the existence of significant rate effects or other non-market returns to education, as the direct level effects that are reflected in wages imply rates of return to schooling that are significantly below those available from alternative assets. 
A comparison between net private and social returns is also of interest to determine to what extent private and social incentives may be misaligned in Europe. But once again, it is not entirely clear what specific rates of return should be used in the comparison. Private incentives are best captured by the unadjusted net private rates of return $(5.90 \%$ to $8.68 \%)$ given in the first block of Table 4, as these reflect the expected benefits that are available to individuals through increased wages. As noted above, these unadjusted private rates of return do not hold physical capital constant, whereas the social rates of return we have computed do. To make them comparable, we need to make some assumption about how the aggregate stock of physical capital will respond to increased investment in education because, given the complementarity between the two types of capital, an increase in the physical capital stock will raise the returns to schooling.

The simplest assumption to make is that the country is a small open economy that has unlimited access to capital at the going world interest rate. Since this is essentially the assumption we made at the microeconomic level, the required adjustment would involve multiplying the social rate of return shown in Table 4 by the inverse of the coefficient we used above to adjust the private rates of return down and would leave the social rate of return above the private return (even taking into account subsidies) starting with relatively low values of the rate effects parameter. At the regional level, where the small open economy assumption is probably a good approximation, this result suggests that there may be reasons for shifting investment priorities from physical to human capital. Indeed, increased subsidies to human capital formation in backward regions may be an effective component of cohesion policies, but two important qualifications to this conclusion should be kept in mind. The first is that there is an element of zero-sum game in this, as the inflow of mobile resources that is likely to follow the increase in human capital investment will come at the expense of other regions. The second is that, as suggested by our discussion of regional externalities in Section $3 \mathrm{~b} . \mathrm{v}$, it is very likely that technology-related externalities operate at the country level rather than at the regional level. Hence, some of the benefits of additional investment in human capital in backward regions may spill over to more advanced ones, thereby reducing the desired impact on regional cohesion.

The case for additional subsidies is considerably weaker when examined from a national or EU-wide perspective. At this level of aggregation, the assumption of perfect capital mobility is probably quite inadequate, as suggested by the high correlation observed between national savings and investment rates. Since these are large economies, they would face an upward sloping supply schedule for capital and would have to rely at least partly on domestic accumulation for increases in the stock of physical capital. As a result, the social return to schooling when we do not hold capital constant may not be much higher than the estimate shown in Table 4 (because the aggregate stock of this factor will increase only gradually and possibly at a higher cost). In this situation, there is a factor that partially 
offsets the externality and it has to do with the fact that individuals and firms (or even regions) are in a better position than countries to exploit the potential benefits of human capital investment because, unlike countries, they have rapid and unlimited access at given prices to complementary inputs whose use will raise the return to educational investment.

Finally, it is worth noting that the (unadjusted) private returns to schooling investment compare rather favourably with the returns on debt and equity, especially if some allowance is made for non-market returns and employment effects. Human capital, however, is a risky asset because there is considerable variation in wages across workers with the same level of educational attainment. Although part of this variation will reflect differences in ability and pay differentials that compensate for various job attributes, individuals are likely to require a sizable risk premium to invest in human capital. Since we lack good measures of the riskiness of such investment, it is not obvious whether the observed pattern of returns makes education a sufficiently attractive investment alternative from an individual point of view. The observed premium over the riskless rate of return (3.2 to 5 percentage points) is comparable to the one on equity or even higher and seems large enough to provide reasonable incentives for investment in education. But it is also true that the expected return on human capital is probably lower than the rate of interest on unsecured personal loans that may be used to finance educational expenditures, when these loans are available at all. Hence, liquidity constraints are more likely to be a problem than low returns per se, particularly in those countries where public student loan programmes do not exist.

Although caution is clearly needed for a number of reasons that have already been discussed (and include the considerable uncertainty that remains about the values of the relevant macroeconomic parameters and the size of the social benefits from human capital not captured by the existing empirical estimates), we believe that the preceding discussion supports the following tentative conclusions:

First, a moderate increase in human capital investment is probably a good idea. The direct economic returns to schooling investment that are captured by macroeconometric studies are comparable to those available from investment in physical capital. When a reasonable allowance is made for the non-market returns to education and for its benefits for social cohesion, human capital becomes a rather attractive investment alternative from a social point of view.

Second, an across-the-board increase in general subsidies to formal education at the postcompulsory level is probably not necessary. This conclusion may be somewhat surprising in view of our emphasis on the importance of human capital externalities, but it must be kept in mind that large subsidies are already in place and that compulsory school attendance also helps to counteract the effects of such externalities. An additional consideration that works in the same direction is that, as we have seen, individuals and firms are in a better position than countries to exploit the potential benefits of human capital investment. These factors 
help explain our finding that the private rate of return relevant for individual schooling decisions compares quite favourably with the social rate of return on education and with those on competing assets available to households.

Hence, the economic incentives for individuals to invest in education are probably adequate. If a further increase in post-compulsory enrollments is considered desirable, it may be more important to eliminate implicit barriers to access to advanced programmes (such as liquidity constraints and lower levels of basic skills for individuals from disadvantaged backgrounds) through policies specifically targeted at these problems, rather than further decrease already low tuition charges that imply a large subsidy for relatively privileged groups. ${ }^{32}$ Indeed, higher tuition fees coupled with a well designed loan programme or with an increase in means-tested grants may be an efficient way to provide additional resources to increase the quality of post-secondary education while at the same time reducing the regressivity of its financing. Additional public funds, however, may be required at lower educational levels and for the expansion of adult training.

It should be stressed that our conclusions are drawn from the analysis of a hypothetical average EU country and, consequently, may have to be modified depending on the particular circumstances of specific countries or regions. In general terms, the case for additional investment in human resources is likely to be stronger in those territories where expenditure is low and/or human capital is scarce relative to other productive assets. Similarly, the need for additional subsidies will vary across countries depending on existing financing arrangements and on the extent to which payscales provide adequate incentives for private investment in education.

\section{Concluding remarks}

Our analysis offers some guidance in identifying the most productive uses of additional educational expenditure as well as changes in current practices that may increase efficiency. Our review of the literature indicates that the most important source of non privately appropriable "excess returns" from human capital investment is likely to be this factor's complementarity with technology. This suggests the following broad objectives for human capital policies. First, aim to give technology-related skills to a broad segment of the population and ensure the adequate supply of technical and scientific personnel needed both for development and for adoption of new technologies. Second, support life-long learning in order to counteract the accelerated depreciation of skills in times of rapid technological change. Third, improve conditions for the accumulation of research-related human capital. Much of this human capital is generated as a by-product of research itself and human capital

32 See for instance OECD (2001b). 
policies should therefore strengthen the link between tertiary education and both private and public research.

The second most important source of aggregate excess returns to human capital is likely to come from its contribution to social cohesion and social capital. Our review of the literature suggests that the objective of enhancing social cohesion and building social capital does not stand in contradiction with human capital policies targeting complementarities between human capital and technology. Giving technology-related skills to a broad majority of the labour force will require policies supporting the acquisition of such skills in segments of the population with historically low levels of human capital and is therefore an opportunity for increasing social cohesion. The complementarity between early human capital and formal education as well as on-the-job training documented in the literature suggests, however, that the success of such policies will depend crucially on generalizing access to early learning opportunities. Research on non-market returns to human capital indicates that early-learning policies will also generate benefits in terms of life-long learning. The complementarity between formal education and on-the-job training suggests moreover that human capital policies should enhance adult learning to prevent marginalization of individuals who have missed the educational opportunities of formal schooling.

Another point that comes out from our review of the literature is that the quality of human capital is likely to be crucial for economic growth. Raising the quality of education should therefore be at the center of human capital policies. Empirical work points towards some concrete steps to accomplish this objective, but considerable uncertainty remains and more research is necessary to identify the determinants of school performance and student achievement. It is already clear, however, that the objective of raising the average quality of human capital does not stand in contradiction with the objective of enhancing social cohesion, as international educational assessment excercises demonstrate that countries with relatively high average achievement are also relatively more successful in raising the performance of students from disadvantaged backgrounds. ${ }^{33}$

On the whole, the evidence we have reviewed is consistent with the view that measures aimed at increasing the quantity and quality of the stock of human capital should be an important part of any growth-promoting policy package. This is certainly so in the case of the Lisbon strategy, which echoes many of the recommendations found in the literature. Implementation of the human capital policies outlined in successive EU summits appears especially important for those regions of the European Union that are lagging behind in productivity and income per capita. It is important to recognize, however, that successful action requires a clear picture of the quantity and quality of regional human capital stocks in order to understand regional needs and to identify those policies that are likely to be most

33 See OECD and Statistics Canada (2000) and OECD (2001c). 
effective. For example, it would be important to extend to the regional level recent studies that have tried to assess the skill levels of younger cohorts and of the workforce at large, and to support further research into the determinants of the performance of educational systems. These studies can be a useful input for the formulation of a systematic human resources policy that should be an important part of the EU's ongoing effort to increase regional cohesion. 


\section{References}

Adelman I. and C. Morris (1967). Society, Politics and Economic Development. The Johns Hopkins University Press, Baltimore, MD.

Aguirregabriria, V. and C. Alonso-Borrego (1997). "Employment Occupational Structure, Technological Capital and Reorganisation of Production." Universidad Carlos III de Madrid, Working Paper No. 97-12.

Alesina A. and E. La Ferrara (2000a). "Participation in Heterogenous Communities." Quarterly Journal of Economics CXV, pp. 847-904

Alesina A. and E. La Ferrara (2000b). "Who Trusts Others?." CEPR Discussion Paper No. 2646.

Alesina A., R. Baqir and W. Easterly (1999). "Public Goods and Ethnic Division." Quarterly Journal of Economics CXIV, pp. 1243-1284.

Altonji, J. and J. Spletzer (1991). "Worker Characteristics, Job Characteristics and the Receipt of On-the-job Training." Industrial and Labor Relations Review 45(1), pp. 58-79.

Allen, Steven (2001). "Technology and the Wage Structure." Journal of Labor Economics 19(2), pp. $440-83$.

Angrist, J.D. and V. Lavy (1996). "The effect of teen childbearing and single parenthood on childhood disabilities and progress in school." NBER Working Paper No. 5807.

Arias, O. and W. McMahon (2001). "Dynamic Returns to Education in the US." Economics of Education Review 20(2), pp.121-38.

Ashenfelter, O., C. Harmon and H. Oosterbeck (1999). "A Review of Estimates of the Schooling/Earnings Relationship, with Tests for Publication Bias." Labour Economics 6(4), pp. 453-70.

Autor, D. H., L. F. Katz and A. B. Krueger (1998). "Computing Inequality: Have Computers Changed the Labor Market?" Quarterly Journal of Economics 113(4), pp. 1169-1214.

Azariadis, C. and A. Drazen (1990). "Threshold Externalities in Economic Development." Quarterly Journal of Economics, May, pp. 501-26.

Barro, R. (1991). "Economic Growth in a Cross Section of Countries." Quarterly Journal of Economics CVI (2), pp. 407-43.

Barro, R. (2000). "Education and economic growth." Mimeo, Harvard University.

Barron, J., D. Black and M. Lowenstein (1993). "Gender Differences in Training, Capital and Wages." Journal of Human Resources 28, pp. 343-64.

Bartel, A. P (1991). "Productivity Gains from the Implementation of Employee Training Programs." NBER Working Paper No. 3893.

Bartel, A. P. and N. Sicherman (1998). "Technological Change and the Skill Acquisition of Young Workers." Journal of Labor Economics, 16(4), pp. 718-755.

Bassanini, A. and S. Scarpetta (2001). "Does human capital matter for growth in OECD countries? Evidence from pooled mean-group estimates." OECD Economics Department Working Paper no. 282. 
Bassi, L., P. Harrison, J. Ludwig, and D. McMurrer (2001). "Human Capital Dynamics Investments and Firm Performance." Human Capital Dynamics.

Baumol, W., S. A. Batey Blackman and E. Wolf (1989). Productivity and American Leadership: the Long View. MIT Press.

Benhabib, J. and M. Spiegel (1994). "The Role of Human Capital in Economic Development: Evidence from Aggregate Cross-Country Data." Journal of Monetary Economics 34, pp. 14373.

Berman, E., J. Bound and S. Machin (1998). "Implications of Skill-Biased Technological Change: International Evidence." Quarterly Journal of Economics, November, pp. 12451280 .

Bils, M. and P. Klenow (2000). "Does schooling cause growth?" American Economic Review 90(5), pp. 1160-83.

Blanchflower, D. and S. Burgess (1998). "New Technology and Jobs: Comparative Evidence from a Two Country Study." Economics of Innovation and New Technology 5(2-4), pp. 10938.

Blau, F. and L. Kahn (1997). "Swimming Upstream: Trends in the Gender Wage Differential in the 1980s." Journal of Labor Economics 15(1), pp. 1-42.

Blechinger, D., A. Kleinknecht, G. Licht and F. Pfeiffer (1998). "The Impact of Innovation on Employment in Europe: An Analysis using CIS Data." Zew Dokumentation Nr. 98-02, Mannheim.

Blundell, R., L. Dearden, C. Meghir, and B. Sianesi (1999) "Human Capital Investment: The Returns from Education and Training to the Individual, the Firm, and the Economy." IFS Working Paper.

Card, D. (1999). "The Causal Effect of Education on Earnings." In O. Ashenfelter and D. Card, editors, Handbook of Labor Economics, vol. 3, chapter 30, pp. 1801-1863. North Holland.

Caroli, E. and J. Van Reenen (1999 ). "Organization, Skills and Technology: Evidence from a Panel of British and French Establishments." The Institute for Fiscal Studies Working Paper Series No. 99/23, London.

Caselli, F., G. Esquivel and F. Lefort (1996) "Reopening the convergence debate: a new look at cross-country growth empirics." Journal of Economic Growth, pp. 363-89.

Cohen, D. and M. Soto (2001). "Growth and human capital: good data, good results." CEPR Discussion Paper no. 3025.

Coleman J. (1988). "Social Capital in the Creation of Human Capital." American Journal of Sociology, 94S, S95-S120.

Coleman J. (1990), "Social Capital." In J. Coleman, Foundations of Social Theory. The Belknap Press of Harvard University Press, Cambridge, Mass., and London, England.

de la Fuente, A. (2002a). "Human capital and growth: a survey and some tentative conclusions." Mimeo, Instituto de Análisis Económico (CSIC), Barcelona.

de la Fuente, A. (2002b). "On the sources of convergence: A close look at the Spanish regions." European Economic Review 46(3), pp. 569-99. 
de la Fuente, A. and R. Doménech (2000). "Human capital in growth regressions: how much difference does data quality make?" OECD Economics Department Working Paper no. 262, Paris.

de la Fuente, A. and R. Doménech (2001). "Educational attainment in the OECD, 1960-90." Mimeo, Instituto de Análisis Económico (CSIC), Barcelona.

Denny, K., C. Harmon and R. Lydon (2001). "Cross-country Evidence in the Returns to Education: Patterns and Explanations." Mimeo.

DiNardo, J. and J. Pischke (1997). "The Returns to Computer Use Revisited: Have Pencils Changed the Wage Structure Too?" Quarterly Journal of Economics 112(1), pp. 291-303.

DiPasquale D. and E.L. Glaeser (1999). "Incentives and Social Capital: Are Homeowners Better Citizens?." Journal of Urban Economics 45, pp. 354-384.

Doménech, R. and J. Boscá (1996). "A Database for the Analysis of Economic Growth in the OECD, 1960-95." Ministerio de Economía y Hacienda, Dirección Gral. de Planificación, Madrid.

Doms, M., T. Dunne and K. Troske (1997). "Workers, Wages and Technology." Quarterly Journal of Economics 112(1), pp. 253-90.

Duguet, E. and N. Greenan (1997). "La biais technologique: Une analyse econometrique sur donnees individuelles. (Skill Bias: An Econometric Analysis at the Firm Level. With English summary.)" Revue Economique 48(5), pp. 1061-89.

Dunne, T., J. Haltiwange and K.Troske (1996). "Technology and Jobs: Secular Changes and Cyclical Dynamics." NBER Working Paper No. 5656..

Entorf, H. and F. Kramarz (1998). "The Impact of New Technologies on Wages: Lessons from Matching Panels on Employees and on Their Firms." Economics of Innovation and New Technology 5(2-4), pp. 165-97.

Entorf, H. and W. Pohlmeier (1990). "Employment, Innovation and Export Activities: Evidence from Firm-Level Data." In J. Florens et al, editors, Microeconometrics: Surveys and Applications, pp. 394-415. Cambridge, Ma. and Oxford.

Entorf, H., M. Gollac and F. Kramarz (1999). "New Technologies, Wages and Worker Selection." Journal of Labor Economics 17(3), pp. 464-91.

European Union (2000). "Presidency conclusions. Lisbon European Council."

Feldman, J., D. Makuc, J. Kleinman and J. Cornoni-Huntly (1989). "National trends in educational differences in mortality." American Journal of Epidemiology 129, pp. 919-933.

Glaeser E. L., D. Laibson, J. A. Scheinkman and C. L. Soutter (2000). "Measuring Trust." Quarterly Journal of Economics CXV, pp. 811-846.

Goldin C. and L. F. Katz (1999). "Human Capital and Social Capital: The Rise of Secondary Schooling in America 1910-1940." Journal of Interdisciplinary History XXIX (4), pp. 683723.

Greenan, N. and D. Guellec (2000). "Technological Innovation and Employment Reallocation." Labour 14(4), pp. 547-90. 
Griliches, Z. (1986). "Economic data issues." In Z. Griliches and M. Intrilligator, editors, Handbook of Econometrics. North Holland, Amsterdam.

Griliches, Z. (1997). "Education, human capital and growth: a personal perspective." Journal of Labor Economics 5(1), pp. S330-S344.

Guiso L., P. Sapienza and L. Zingales (2000), "The Role of Social Capital in Financial Development." NBER Working Paper No. 7563.

Hanushek, E. and D. Kimko (2000). "Schooling, labor-force quality and the growth of nations." American Economic Review 90(5), pp. 1184-208.

Harkness, S. (1996). "The Gender Earnings Gap: Evidence from the UK." Fiscal Studie. 17(2), pp. 1- 36.

Harmon, C., I, Walker and N. Westergaard-Nielsen (2001). "Returns to education in Europe." In Public funding and private returns to education. PURE final report.

Heckman, J., L. Lochner and P. E. Todd (2001). "Fifty Years of Mincer Earnings Regressions." Working Paper, University of Chicago.

Helliwell J. F. (1996). "Do Borders Matter for Social Capital? Economic Growth and Civic Culture in U.S. States and Canadian Provinces." NBER Working Paper No. 5863.

Helliwell J. F. (1996). "Economic Growth and Social Capital in Asia." NBER Working Paper No. 5470.

Helliwell J. F. and R. D. Putnam (1999). "Education and Social Capital." NBER Working Paper No. 7121.

Heinrich, G. and V. Hildebrand (2001). Public and Private Retunrs to Education in the European Union - An appraisal. European Investment Bank, Luxembourg.

Islam, N. (1995). "Growth empirics: a panel data approach." Quarterly Journal of Economics 110, pp. $1127-70$.

Jones, C. (1996). "Human capital, ideas and economic growth." Mimeo, Standford University.

Jones, C. Jones, C. (2002). "Sources of U.S. economic growth in a world of ideas." American Economic Review 92(1), pp. 220-39.

Katz, L. and K. Murphy (1992). "Changes in Relative Wages. 1963-1987: Supply and Demand Factors." Quarterly Journal of Economics 107(1), pp. 35-78.

Krueger, A. (1993). "How Have Computers Changed the Wage Structure: Evidence from Micro Data, 1984-89." Quarterly Journal of Economics 108(1), pp. 33-61.

Krueger, A. and M. Lindahl (2001). "Education for growth: why and for whom?" Journal of Economic Literature XXXIX, pp. 1101-36.

Kyriacou, G. (1991). "Level and Growth Effects of Human Capital, A Cross-Country Study of the Convergence Hypothesis." Mimeo, New York University.

La Porta R., F. Lopez-de-Silanes, A. Shleifer, and R. Vishny (1997). "Trust in Large Organizations." American Economic Review Papers and Proceedings 87 (2), pp. 333-338. 
Landau, D. (1983). "Government Expenditure and Economic Growth: a Cross-Country Study." Southern Economic Journal, January, pp. 783-92.

Lee, D. W. and T. H. Lee (1995). "Human capital and economic growth. Tests based on the international evaluation of educational achievement." Economics Letters 47, pp. 219-25.

Lee, J. W. and R. Barro (2001). "Schooling quality in a cross-section of countries." Economica 68, pp. 465-88.

Lucas, R. (1988). "On the Mechanics of Economic Development." Journal of Monetary Economics 22, pp. 3-42.

Lynch and Black (1995). "Beyond the Incidence of Training: Evidence from a National Employers Survey." NBER Working Paper No. 5231.

Lynch, L. (1992). "Private-Sector Training and the Earnings of Young Workers." American Economic Review 82, pp. 299-312.

Machin, S. and J. Van Reenen (1998). "Technology and Changes in Skill Structure: Evidence from Seven OECD Countries." Quarterly Journal of Economics 113(4), pp. 1215-44.

Mankiw, G., D. Romer and D. Weil (1992). "A Contribution to the Empirics of Economic Growth." Quartely Journal of Economics, pp. 407-37.

McMahon, W. (1991). "Relative returns to human and physical capital in the US and efficient investment strategies." Economics of Education Review 10(4), pp. 283-96.

McMahon, W. (1998). "Conceptual framework for the analysis of the social benefits of lifelong learning." Education Economics 6(3), pp. 309-346.

Mincer, J. (1974). Schooling, experience and earnings. Columbia University Press, New York.

Mincer J. (1993). "Human Capital, technology and the wage structure: What do Time Series Show?." In J. Mincer. The Collected Essays of Jakob Mincer, Chap. 13. Aldershot, England.

Nelson, R. and E. Phelps (1966). "Investment in Humans, Technological Diffusion, and Economic Growth." American Economic Review, May, pp. 69-82.

OECD (1999). OECD science, technology and industry scoreboard-- benchmarking knowledgebased economies. Paris.

OECD (2001a). The new economy: beyond the hype. The OECD growth project. Paris.

OECD (2001b). "Investment in Human Capital through Post-compulsory Education and Training," Doc. ECO/CPE/WP1(2001)12 and ECO/CPE/WP1(2001)12/ ANN1.

OECD (2001c). Knowledge and Skills for Life, First Results from PISA 2000, Programme for International Student Assessment. Paris.

OECD and Statistics Canada (2000). Literacy in the information age. Final report of the International Adult Literacy Survey. Paris.

Pritchett, L. (1999). "Where has all the education gone?" Mimeo, World Bank.

Psacharopoulos, G. (1994). "Returns to investment in education: a global update." World Development 22(9), pp. 1325-43. 
Putnam R. (1993a). Making Democracy Work: Civic Traditions in Modern Italy, Princeton, Princeton University Press.

Putnam R. (1993b). "The Prosperous Community: Social Capital and Public Life." The American Prospect 13, pp. 35-42.

Putnam R. (1995a). "Bowling Alone: America's Declining Social Capital." Journal of Democracy 6(1), pp. 65-78

Putnam R. (1995b). "The Case of Missing Social Capital." Working Paper, Harvard University.

Putnam R. (1996). "The Strange Disappearance of Civic America." The American Prospect $7(24)$.

Putnam R. (2000). Bowling Alone: The Collapse and Revival of American Community, Simon and Schuster, New York.

Romer, P. (1989). "Human Capital and Growth: Theory and Evidence." NBER Working Paper No. 3173.

Solomon, L.C. (1975). "The relation between schooling and saving behavior." In F.T. Juster, Education, income, and human behavior. McGraw-Hill, New York.

Temple J., and P. Johnson (1998). "Social Capability and Economic Growth." Quarterly Journal of Economics, August, pp. 965-990.

Temple, J. (2001). "Growth effects of education and social capital in the OECD." Mimeo, forthcoming in OECD Economic Studies.

Topel, R. (1999). "Labor markets and economic growth." In O. C. Ashenfelter and D. Card, editors, Handbook of Labor Economics, Vol. 3. North Holland, Amsterdam.

Uzawa, H. (1965). "Optimum Technical Change in an Aggregative Model of Economic Growth." International Economic Review 6(1), pp. 18-31.

Welch, F. (1970). "Education in Production." Journal of Political Economy 78, pp. 35-59.

Wolfe, B. and S. Zuvekas (1997). "Non-market outcomes of schooling." International Journal of Education Research 27, pp. 491-502.

World Bank (2002). Social Capital Home Page: http://www.worldbank.org/poverty/ scapital/index.htm.

Wössmann, L. (2000). "Specifying human capital: a review, some extensions and development effects." Kiel Working Paper no. 1007.

Zak, P. J. and S. Knack (2001). "Trust and Growth." Economic Journal 111, pp. 295-321. 